\title{
Review on PCL, PBS, and PCL/PBS blends containing carbon nanotubes
}

\author{
T. P. Gumede ${ }^{1}$, A. S. Luyt ${ }^{*}$, A. J. Müller $r^{3,4}$ \\ ${ }^{1}$ Department of Chemistry, University of the Free State (Qwaqwa Campus), Private Bag X13, 9866 Phuthaditjhaba, \\ South Africa \\ ${ }^{2}$ Center for Advanced Materials, Qatar University, P.O. Box 2713, Doha, Qatar \\ ${ }^{3}$ POLYMAT and Polymer Science and Technology Department, Faculty of Chemistry, University of the Basque Country \\ UPV/EHU, Paseo Manuel de Lardizabal 3, 20018. Donostia-San Sebastián, Spain \\ ${ }^{4}$ IKERBASQUE, Basque Foundation for Science, 48013 Bilbao, Spain
}

Received 31 October 2017; accepted in revised form 17 January 2018

\begin{abstract}
Biodegradable polymers received considerable attention due to their contribution in the reduction of environmental concerns and the realization that global petroleum resources are finite. The development of double crystalline biobased blends such as poly( $\varepsilon$-caprolactone) (PCL) and poly(butylene succinate) (PBS) are particularly interesting because each component has an influence on the crystallization behaviour of the other component, and thus influences the strength and mechanical properties of a polymer blend. The lack of miscibility between PCL and PBS constitutes a bottleneck, and efforts have been made to improve the miscibility through the inclusion of copolymers. Having realized that incorporating conductive nanofillers such as carbon nanotubes (CNTs), (especially when the CNTs are functionalized or used as a masterbatch i.e., polycarbonate/MWCNTs masterbatch), into biopolymer matrices, can enhance the thermal and mechanical properties, as well as electrical and thermal conductivity, a lot of research was aimed at the production of bionanocomposites. This review paper discusses the properties of PCL, PBS, their blends, and their CNTs containing nanocomposites.
\end{abstract}

Keywords: nanocomposites, poly(E-caprolactone), poly(butylene succinate), polycarbonate, carbon nanotubes

\section{Introduction}

Most plastic products that are used in our everyday lives such as polypropylene (PP), polyethylene (PE), polystyrene (PS), polyvinyl chloride (PVC) and polyethylene terephthalate (PET) are derived from petrochemical resources [1]. Fossil fuel and natural gases are the basic raw materials for the synthesis of petroleum based polymers. These polymers have excellent mechanical properties, good thermal stability, and chemical and biological inertness, and they have wide applications in the packaging industry (bottles, plastic bags, etc.). They are, however, resistant to biodegradation and they survive in the environment for a long time, forming a significant part of municipal solid waste, due to the difficulty of recycling or reuse caused by various levels of contamination [2]. Packaging industries use up to $40 \%$ of produced plastics for short service life applications, and most of these plastics end up in landfills. Some of these polymers end up in the aquatic environment, and they pollute water. During incineration of these petroleum based plastics, harmful gases like carbon dioxide $\left(\mathrm{CO}_{2}\right)$, carbon monoxide $(\mathrm{CO})$, dioxins and furans are released, and these are the major causes of atmospheric pollution, which leads to the deterioration of the ozone layer, resulting in climate change. There is thus a need to develop biodegradable polymers with similar functionality as petrochemical polymers, but that are 
readily susceptible to microbial action. This will contribute to a reduction in the environmental pollution caused by plastic waste, and also conserve petrochemical resources [2-5].

Biodegradable polymers are mainly synthesized from renewable natural resources and they degrade over a period of time through enzymolysis of microorganisms when exposed to a natural environment [2]. Different types of biodegradable polymers such as poly(E-caprolactone) (PCL), poly(butylene succinate) (PBS), poly(lactic acid) (PLA), and poly(alkanoates) (PHA, PHB, PHBV) have been studied as potential biomaterials for a variety of applications such as biomedical devices, biodegradable packaging, adhesives, agricultural areas, auto-motion and construction [6-10]. However, some of these applications are limited due to the polymers' poor thermal and mechanical properties such as brittleness, low toughness and slow crystallization rates. Amongst the commercial biodegradable polymers, PCL received the most attention due to its elasticity, biocompatibility and good ductility caused by its low glass transition temperature $\left(T_{\mathrm{g}}\right)$ of $-60^{\circ} \mathrm{C}$. It is easy to be melt processed by extrusion, melt-spinning, film blowing and injection moulding, but it has relatively low mechanical strength which limits some practical applications.

Polymer blending is a useful method for achieving a desirable combination of properties, that are often absent in the neat polymers. It offers advantages such as cost effectiveness and less time-consumption compared to the development of new monomers as a basis for new polymeric materials. Additionally, a wide range of material properties is within reach by merely changing the blend composition [11]. PCL was blended with various other biodegradable polymers in a number of studies [12-22]. Amongst various biodegradable polymers, PBS was the most interesting aliphatic polyester due to its relatively good melt processability, thermal and chemical resistance, biodegradability, and excellent mechanical properties, closely comparable to those of the widely-used polyethylene (PE) and polypropylene (PP) $[4,5,15$ 21, 23-36]. Double crystalline PCL/PBS blends are particularly interesting because each component has an influence on the crystallization behaviour of the other component. Crystallinity and crystalline morphology have an influence on the strength and mechanical properties of a polymer blend, and it is therefore important to understand the influence of the other component in a blend on the crystallization behaviour of a particular component. Although blending is a good method for improving the properties of the individual polymers, the PCL/PBS blends are immiscible as evidenced by composition independent $T_{\mathrm{g}} \mathrm{S}$ and a biphasic melt, which leads to poor interfacial adhesion and macrophase separation. Several methods, such as the addition of the copolymers (poly (ethylene oxide)-block-poly(propylene oxide)-blockpoly(ethylene oxide) (PEO-PPO-PEO) and poly(butylene succinate-co- $\varepsilon$-caprolactone) (P(BS-co-CL)) and thermoplastic soy meal (TSM), have been applied to improve miscibility, interfacial adhesion and the resultant mechanical properties of PCL/PBS blends [16, 20, 21].

Recent reports [37-39] revealed that adding conductive carbon-based nano-fillers such as carbon nanotubes (CNTs) into PCL and PBS matrices can enhance some of the matrix properties to better levels than those of the copolymers or polymers filled with metal powders, as well as produce electrically conductive materials with better mechanical properties. This is due to their low density, inertness and better compatibility than metal powders with most polymers. CNTs have shown to have greater potential than any other carbon-based nano-fillers (i.e., carbon black (CB), carbon nanofibres (CNF), and graphite) because of their unique one-dimensional structure with good electrical conductivity, as well as excellent mechanical and thermal properties [40-42]. These improved properties depend not only on the unique mechanical strength, large aspect ratio, and excellent thermal and electrical conductivities, but also on the alignment, adhesion, and dispersion in the polymer matrix. The enhanced mechanical properties, thermal properties and conductivity enable the PBS/CNTs nanocomposites to be used in industry fields, as well as in tissue engineering scaffolds or drug delivery systems. The potential applications for PCL/CNTs nanocomposites include vapour sensors, electromagnetic interference shielding and structural biomaterials for tissue engineering when electro-spun into membranes. PCL/PBS/CNTs nanocomposites can be used as biomaterials in applications such as tissue engineering, stent materials or drug delivery systems where their crystallinities, thermomechanical properties and biodegradation rates can be tailored according to the intended use. CNTs are extremely strong and stiff nanostructures of carbon atoms arranged in a cylindrical hexagonal network, and are 
often categorized in two different groups: singlewalled carbon nanotubes (SWCNTs) and multi-walled carbon nanotubes (MWCNTs). SWCNTs consist of a single graphene layer rolled up into a seamless cylinder, whereas MWCNTs consist of two or more concentric cylindrical shells of graphene sheets coaxially arranged around a central hollow core with van der Waals forces between adjacent layers. MWCNTs are the ideal choice for high-volume industrial applications due to their bulk availability and better dispersion compared to SWCNTs [39, 43].

Despite the advantages of carbon nanotubes, they have a tendency to form aggregates during mixing with polymers. This is due to the van der Waals attraction between the nanotubes, which makes it difficult for them to be dispersed into polymers. This has been a major drawback in the development of CNTbased polymeric nanocomposites. Several methods have been employed to enhance the dispersion of MWCNTs into polymer matrices, such as (i) treatment of CNTs with inorganic solvents (nitric acid $\left(\mathrm{HNO}_{3}\right)$, sulphuric acid $\left(\mathrm{H}_{2} \mathrm{SO}_{4}\right)$ and phosphoric acid $\left.\left(\mathrm{H}_{3} \mathrm{PO}_{4}\right)\right)$ in order to attach hydroxyl and carboxylic acid functional groups to the nanotubes, and (ii) the masterbatch approach, which is a direct encapsulation of the CNTs into a polymer matrix, and the subsequent release of the carbon nanotubes into the polymer matrix during mixing in the melt. The masterbatch method has received great interest from an industrial point of view, because it does not involve solvents that are harmful to the environment [43-45]. The ultimate properties of the nanocomposites are dependent on the processing methods and processing conditions. Most CNTs/polymer nanocomposites were processed using the following methods: melt blending, solution mixing and in situ polymerization [43, 46, 47]. Melt blending is one of the most economical and environmentally friendly methods of fabricating composites. The compounding is generally achieved in a single or twin-screw extruder where the polymer and the nanoparticle mixture are heated to form a melt. The mixer imparts shear and elongational stress to the process, helping to break apart the filler agglomerates and uniformly dispersing them in the polymer matrix. Another advantage of melt processing is that it does not require the use of organic solvents during processing. The compounded nanoparticle-polymer composite can be further processed using other polymer-processing techniques such as injection moulding, profile extrusion, blow moulding and hydraulic melt pressing. This is the processing method of choice for most industries [39]. Solution mixing is the most common method used for small-scale processing, while in situ polymerization has also been used. These two techniques are, however, not commercially viable and they are environmentally unfriendly, due to the use of toxic and/or volatile solvents. This review will explore the morphology and physical properties of PCL, PBS, their blends and their CNTs containing nanocomposites.

\section{PCL/PBS blends}

\subsection{Morphology}

Polymers are often blended together to improve the thermal and mechanical properties of the final product. The morphology of the polymer blend plays a critical role in understanding the structure-property relationships between the blend components, and hence there has been much research on structure development in such blends. Several studies were conducted on evaluating the morphology of PCL/PBS blends by employing scanning electron microscopy (SEM) and polarized light optical microscopy (PLOM) [16, 17, 19-21, 27]. These blends were mostly prepared through melt blending and solution mixing methods. Regardless of the preparation method used, the morphologies of the blends were found to depend on the ratios of the components in the blend, their viscosities, and the interfacial tension between the component phases $[27,48]$. Depending on the $\mathrm{PCL} / \mathrm{PBS}$ blend ratios, the minor component generally formed discrete spherical domains in a matrix of the major component, which indicates poor interfacial interactions between the components. This implied that PCL/PBS blends are immiscible because of the biphasic separation between the components in the blend. The non-uniform distribution of the spherical domains is a result of the difference between the melt viscosities of PCL and PBS [27].

Immiscible polymer blends need to be compatibilized in order to achieve better interfacial interaction between the blend components. The compatibilization can be achieved through (i) optimization of the interfacial tension, (ii) stabilizing the morphology against high stresses, and (iii) enhancing the adhesion between the component phases. A number of studies investigated the effect of adding a compatibilizer on the morphologies of PCL/PBS blends [16, 20, 21]. In these studies, copolymers (PEO-PPO$\mathrm{PEO}$ and $\mathrm{P}(\mathrm{BS}-\mathrm{co}-\mathrm{CL})$ ) and thermoplastic soy meal 
(TSM) were used as compatibilizers. The compatibilizer was generally found to encapsulate itself between the polymer phases, reducing the spherical particle sizes and increasing the surface contact area between the blend components. In some cases, the addition of the compatibilizer resulted in the disappearance of the spherical domains, exhibiting a rougher fracture surface than the blend without the compatibilizer. This apparently confirmed the effective reduction of interfacial tension and a significant improvement in compatibility and interfacial adhesion [20]. Some researchers studied ternary blends of PCL and PBS with PLA or a copolyester of adipic acid, terephthalic acid, and 1,4-butanediol (EASTAR) as a third component [27]. The third component was also located at the interface of the PCL/PBS blends, demonstrating a three-phase line of contact at the interface, with improved intermolecular interactions.

\subsection{Mechanical properties}

The mechanical properties of immiscible polymer blends depend on the intermolecular forces, chain stiffness and the crystalline nature of the individual components in the blend [27]. Very few studies reported the mechanical properties of PCL/PBS blends, with the available reports showing tensile testing and dynamic mechanical analysis results [16, 20, 21, 27]. The tensile strength was found to decrease as the PCL content increased in the blends, while the elongation at break and impact strength increased with increasing PCL content. The decreased tensile strength indicated poor interfacial interactions between the blend phases. The higher elongation values showed improved ductility and toughness in the blends, due to the plasticization by PCL, which led to improved chain mobility and energy absorbed by the material before fracturing.

When a $\mathrm{P}(\mathrm{BS}-\mathrm{co}-\mathrm{CL})$ compatibilizer was added in amounts up to $5 \mathrm{wt} \%$ in a $80 / 20 \mathrm{w} / \mathrm{w}$ PBS/PCL blend system, the modulus of elasticity, yield stress and fracture strain dramatically increased with increasing compatibilizer content [21]. This behaviour was attributed to the improved interfacial compatibility in the presence of the compatibilizer. However, the properties declined significantly with further increases in the compatibilizer content, but no explanation was offered for this observation. It is well known that the effectiveness of a compatibilizer depends on the content added in the blend, and in this case saturation was probably reached at $5 \mathrm{wt} \%$ content.
Since immiscibility of polymer blends strongly affect its mechanical properties, the effect of a compatibilizer on the thermo-mechanical properties of PCL/ PBS blends was investigated by dynamic mechanical analysis (DMA) [20]. When PEO-PPO-PEO was used as a compatibilizer in PCL/PBS blends with different ratios, the storage modulus $\left(E^{\prime}\right)$ values decreased with increasing PCL content. This result was attributed to the plasticizing effect of the copolymer backbone of the compatibilizer, that caused homogeneity in the sequence lengths. In the loss modulus $\left(E^{\prime \prime}\right)$ curves, both the PBS and PCL glass transition peaks were present, especially for the $20-40 \%$ PCL blends. This indicated that there was limited phase mixing of PCL and PBS. However, in the presence of the compatibilizer, the $E^{\prime \prime}$ value for PBS shifted to lower temperatures with increasing PCL content, while the $E^{\prime \prime}$ value for PCL slightly increased compared to that of neat PCL. This indicated interaction and compatibility between the two polymers in the presence of the compatibilizer.

\subsection{Melting and crystallization behaviour}

The immiscible nature of the two phases in the blends influence the thermal behaviour of the PCL/PBS blends. Several authors investigated the effect of blend composition, cooling and heating rates on the melting and crystallization behaviour of PCL/PBS blends $[16,19-21,27]$. The non-isothermal crystallization behaviour of PCL/PBS blends was studied using differential scanning calorimetry (DSC). Generally, the blends were cooled from the melt at various cooling rates of 2,5 and $10^{\circ} \mathrm{C} \cdot \mathrm{min}^{-1}$, and the subsequent melting behaviour was investigated at a heating rate of $20^{\circ} \mathrm{C} \cdot \mathrm{min}^{-1}$. Two crystallization peaks were reported for the non-isothermal crystallization of these blends, corresponding to the crystallization of PBS and PCL, respectively. The crystallization peak temperature of PBS was higher than that of PCL, and the crystallization peak temperatures for PCL and PBS in the blends remained almost the same as those of the neat materials, which confirmed the blend immiscibility. However, the crystallization exotherm of PCL in a 40/60 w/w PCL/PBS blend split into two peaks, although no explanation was given for this observation [19]. One possible explanation could be fractional crystallization, indicating better dispersion and a significant improvement in the interfacial adhesion compared to the PCL rich blends. For a given blend composition, the crystallization peak 
temperatures of PCL and PBS shifted to lower temperatures with increasing cooling rate due to supercooling.

The melting behaviour of the PCL/PBS blends, after the completion of the non-isothermal crystallization at various cooling rates, was also studied by DSC. Generally, two separate melting endotherms were reported for all the blends independent of the cooling rate used, corresponding to the melting of $\mathrm{PCL}$ at the lower temperature and PBS at the higher temperature. Double melting endotherms, or one main melting endotherm with a shoulder on the left side of the main melting peak, were found for PBS, and the ratio of the areas of the two melting peaks was influenced by the cooling rate used and the blend composition. The lower temperature melting peak was ascribed to the melting of the PBS crystals formed during the cooling process from the melt, while the higher temperature melting peak was attributed to the recrystallization-melting of the material which melted at the lower temperature. At a given cooling rate, and for a given blend composition, the ratio of the area of the lower melting peak to that of the higher melting peak decreased with increasing PCL content, indicating that the crystallization of PBS from the melt was hindered by the presence of PCL, especially during fast cooling, because less time was available for the crystallization of PBS.

In the case of the melting of PCL, only one well-defined melting peak was reported for the PCL-rich blends $(100 / 0,80 / 20,60 / 40 \mathrm{w} / \mathrm{w})$ at cooling rates of 2 and $5{ }^{\circ} \mathrm{C} \cdot \mathrm{min}^{-1}$, while a main melting peak with a small shoulder on the right side of the main melting peak was reported at a faster cooling rate of $10^{\circ} \mathrm{C} \cdot \mathrm{min}^{-1}[19]$. For the PBS-rich blends $(40 / 60$ and $20 / 80 \mathrm{w} / \mathrm{w}$ ), two melting peaks were reported for PCL independent of the cooling rate used. This double melting behaviour was ascribed to a melting-recrystallization mechanism. However, the blend composition also played an important role in the melting behaviour of the two components. When the content of the other component was higher in the blends, the appearance of a double melting peak due to meltingrecrystallization was more pronounced. The degree of crystallinity $\left(X_{\mathrm{c}}\right)$ of the components in the blends was calculated using Equation (1):

$$
X_{\mathrm{c}}[\%]=\frac{\Delta H_{\mathrm{m}}}{\Delta H_{\mathrm{m}, 100} \cdot W_{\mathrm{f}}} \cdot 100
$$

where $\Delta H_{\mathrm{m}}$ was the melting enthalpy, $W_{\mathrm{f}}$ the weight fraction of PCL or PBS in the blends, and $\Delta H_{\mathrm{m}, 100}$ was the melting enthalpy for $100 \%$ crystalline polymer. For PBS, $\Delta H_{\mathrm{m}, 100}$ was taken as $110 \mathrm{~J} \cdot \mathrm{g}^{-1}$, which was calculated through extrapolation. For PCL, $\Delta H_{\mathrm{m}, 100}$ was taken as $136 \mathrm{~J} \cdot \mathrm{g}^{-1}$. The degree of crystallinity of PBS in the blend remained almost the same and was independent of the blend composition, while the degree of crystallinity of PCL in the blends decreased sharply, especially for the $60 / 40 \mathrm{w} / \mathrm{w}$ PBS/ PCL blend, indicating that the presence of a high PBS content had a significant negative influence on the crystallization of PCL. PBS also showed a cold crystallization peak, which was enhanced by the addition of PCL. It was probably the larger free volume created by the molten PCL, which improved the mobility of the PBS chains and gave rise to its crystallization during heating.

The melting and crystallization behaviour of the PCL/PBS blends compatibilized with PEO-PPO-PEO and $\mathrm{P}(\mathrm{BS}-\mathrm{co}-\mathrm{CL})$ copolymers was reported in some studies $[20,21]$. The melting and crystallization temperature of PBS generally decreased in the presence of a PEO-PPO-PEO compatibilizer, which was attributed to the plasticizing effect of the copolymer backbone of the compatibilizer that caused homogeneity in the sequence lengths. However, there was no significant change in the melting temperature of PCL in the blends. It was further observed that the percentage crystallinity of PBS was influenced differently by the presence and amount of PCL in the blends, depending on whether the blends were compatibilized or noncompatibilized. This value increased with increasing PCL content throughout the composition range for the compatibilized blends, but for the non-compatibilized blends it increased with increasing PCL content up to $30 \mathrm{wt} \%$, after which it declined. This indicates a saturation point due to limited phase mixing [20]. The addition of $5 \mathrm{wt} \% \mathrm{P}(\mathrm{BS}-\mathrm{co}-\mathrm{CL})$ compatibilizer to a blend composition of 20/80 w/w PCL/PBS was found to result in a stronger interaction between the two components compared to 2 and $8 \mathrm{wt} \%$ compatibilizer contents. The latter two compatibilizer contents seemed to have retarded the crystallization of PBS and enhanced that of PCL in the blend [21].

\section{PCL/PC blends}

This section describes previous research on polycarbonate (PC)/PCL blends, because of the effective use 
of $\mathrm{PC}$ as matrix polymer in the preparation of CNTs masterbatches $[49,50]$. The PC/CNTs masterbatch can be added to PCL to improve the dispersion of CNTs in the PCL matrix.

\subsection{Miscibility assessment}

The most widely used method to evaluate whether miscibility was achieved, is by measuring the glass transition temperature. The $\mathrm{PCL} / \mathrm{PC}$ blend system is an example in which homogeneous mixing of the components in the melt and in the amorphous phase, over the whole composition range, is envisaged [5157]. PCL/PC blends were found to be miscible, because a single $T_{\mathrm{g}}$, that varied with composition between those of the neat components, was observed (Figure 1). This is because, upon cooling, the amorphous phase remained a homogeneous mixture of the two polymers. Since the $T_{\mathrm{g}}$ of PCL is much lower than that of PC, the $T_{\mathrm{g}}$ of the blends decreased upon the addition of PCL to PC. The low $T_{\mathrm{g}}$ of PCL enabled the $\mathrm{PC}$ to crystallize at a rate that was much higher than that for neat PC, indicating that the PCL acted as a very effective macromolecular plasticizer $[51,53]$. Even though PCL and PC have been reported to be miscible, some authors [50] reported partial miscibility, where two phases were formed (PC-rich and PCL-rich phases). In the PC-rich phase, the small amount of PCL chains included within this phase plasticized the PC component and the PC-rich phase was therefore able to crystallize. In contrast, in the PCL-rich phase, the presence of PC chains caused changes in the glass transition temperature of the PCL phase that were much smaller than those predicted by the Fox equation.

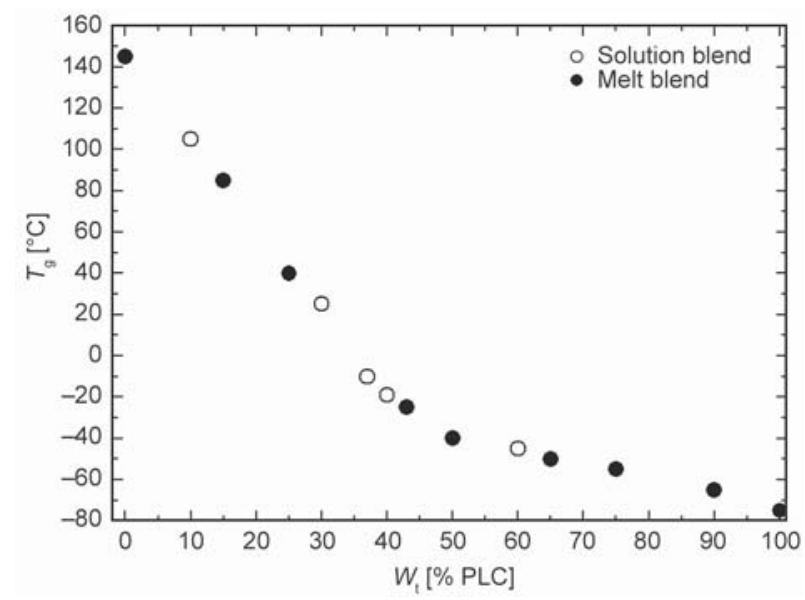

Figure 1. Effect of overall blend composition on the $T_{\mathrm{g}}$ observed by differential thermal analysis (DTA) on melt- and solution mixed blends [54].
Several equations were proposed to predict the values of the glass transition temperature for miscible polymer blends [51-53, 58]. The earliest of these equations was the Fox equation (Equation (2)):

$\frac{1}{T_{\mathrm{g}}}=\frac{w_{1}}{T_{\mathrm{g} 1}}+\frac{w_{2}}{T_{\mathrm{g} 2}}$

where $T_{\mathrm{g}}$ is the glass transition of the blend, and $T_{\mathrm{gi}}$ and $w_{\mathrm{i}}$ are the respective glass transitions and weight fractions of the components in the blend. For most blends, positive or negative deviations were observed from the Fox equation, because this equation does not take into account the interaction between the components. Another equation, which does factor in this interaction, is the Gordon-Taylor equation (Equation (3)):

$T_{\mathrm{g}}=\frac{w_{1} T_{\mathrm{g} 1}+K w_{2} T_{\mathrm{g} 2}}{w_{1}+k w_{2}}$

where $K$ is a dimensionless binary constant described by Equation (4):

$K=\frac{\Delta \gamma_{2} V_{2}}{\Delta \gamma_{1} V_{1}}$

where $\Delta \gamma_{i}$ is the change in the volumetric expansion coefficient at the glass transition temperature of each component, and $V_{\mathrm{i}}$ are their specific volumes. This equation was originally derived for random copolymers, and can be used to describe the composition dependence of miscible polymer blends exhibiting negative or positive deviations if $K$ is treated as an adjustable parameter. However, it should only be applied to blends and mixtures with relatively weak specific intermolecular interactions. These classical equations predict that $T_{\mathrm{g}}$ increases continuously (smoothly) and monotonically with composition. However, it has been reported that the $T_{\mathrm{g}}$-composition variation of several polymer blend systems is not monotonic and exhibited a cusp at a certain critical composition. This phenomenon became very prominent when the $T_{\mathrm{g}}$ difference between the two homopolymers exceeded $50^{\circ} \mathrm{C}$. The classical equations became invalid below a critical temperature, $T_{\mathrm{c}}$, as the free volume of the high $T_{\mathrm{g}}$ component became zero. The relationship between the critical temperature and the composition is given by the Kovacs expression (Equation (5)):

$T_{\mathrm{c}}=T_{\mathrm{g} 2}-\frac{f_{\mathrm{g} 2}}{\Delta \gamma_{2} V_{2}} \quad$ if $T_{\mathrm{g} 2}>T_{\mathrm{g} 1}$ 
where $\Delta \gamma_{2} V_{2}$ is the difference between the volume expansion coefficients in the glassy and liquid states of component 2 , and $f_{\mathrm{g} 2}$ is the free volume fraction of polymer 2 at $T_{\mathrm{g} 2}$. Below $T_{\mathrm{c}}$, the $T_{\mathrm{g}}$ is described by Equation (6):

$T_{\mathrm{g}}=T_{\mathrm{g} 1}+\frac{f_{\mathrm{g} 1}}{\Delta \gamma_{1} V_{1}} \frac{\phi_{2}}{\phi_{1}}$

According to this equation, the $T_{\mathrm{g}}$ of the blend is uniquely determined by the properties of the low $T_{\mathrm{g}}$ polymer at temperatures below $T_{\mathrm{c}}$ or at compositions below $\phi_{\mathrm{c}}$. For excess volume between the two polymers upon mixing, Braun and Kovacs derived Equation (7):

$T_{\mathrm{g}}=T_{\mathrm{g} 1}+\frac{\phi_{2} f_{\mathrm{g} 2}+g \phi_{1} \phi_{2}}{\phi_{1} \Delta \gamma_{1} V_{1}}$

where $g$ is an interaction term defined by Equation (8):

$$
g=\frac{\frac{V_{\mathrm{e}}}{V}}{\phi_{1} \phi_{2}}
$$

where $V_{\mathrm{e}}$ is the excess volume and $V$ the volume of the blend. The excess volume of $g$ is positive if blend interactions are stronger than those between the homopolymers. $g$ is obtained by fitting the $T_{\mathrm{g}}$-composition data to the Braun-Kovacs equation. Even though the literature conflicts in some aspects such as different methods used for preparing the blends, solution- or melt mixing, and the compositional variation of the glass transition, Cheung and co-workers [52] concluded that the Fox equation can only accurately predict the glass transition temperature for compositions above $70 \% \mathrm{PC}$ and that the Braun-Kovacs expression should be used in the other range. In contrast, Balsamo et al. [53] and Ketelaars et al. [51] accurately described the compositional variation with the Fox equation over the entire composition range.

\subsection{Melting behaviour}

The melting behaviour of the components in the blend was investigated in several studies $[53,54$, 56]. In order to evaluate the miscibility in polymer blends, the equilibrium melting temperature $\left(T_{\mathrm{m}}^{\mathrm{o}}\right)$ was determined [53, 54]. Two different approaches are often used to obtain the equilibrium melting point. In the Gibbs-Thompson approach, $T_{\mathrm{m}}^{\mathrm{o}}$ is obtained from the intercept of a plot of the reciprocal of lamellar thickness versus $T_{\mathrm{m}}$. The most popular approach is the Hoffman-Weeks extrapolation, in which $T_{\mathrm{m}}^{\mathrm{o}}$ is derived from a plot of apparent $T_{\mathrm{m}}$ versus $T_{\mathrm{c}}$, the values of which are obtained after isothermal crystallization. The temperature at which the experimental $T_{\mathrm{m}}$ versus $T_{\mathrm{c}}$ line intercepts the $T_{\mathrm{m}}=T_{\mathrm{c}}$ line gives the equilibrium melting point. There are conflicting reports in the literature on certain aspects, such as the depression of the equilibrium melting temperature of one or more components in compositions where crystallization is possible, for example in PCL/PC blends where PCL was the major component. In [53, 54], an equilibrium melting temperature depression was reported for both the PCL and PC components as the content of the other component increased. This decrease was attributed to (i) the reduction in the chemical potential of the component in the amorphous phase caused by the diluent polymer, (ii) polymer-polymer interactions, and (iii) lack of influence of morphological effects such as lamellar thickening and crystal perfection. However, in [56] no melting temperature depression was reported for either PCL or $\mathrm{PC}$, and the authors concluded that the Flory interaction parameter, $\chi$, for this PCL/PC blend system was possibly zero or slightly positive. Other authors were not able to perform the calculation of the FloryHuggins interaction parameter, $\chi$ from Equation (9). This was due to a nonlinear dependence of the curves in a plot of $\left(1 / T_{\mathrm{mb}}^{\mathrm{o}}\right)-\left(1 / T_{\mathrm{m}}^{\mathrm{o}}\right)$ versus $\phi_{\mathrm{a}}^{2}$, suggesting that the interaction parameter could be composition dependent [53]:

$\frac{1}{T_{\mathrm{mb}}^{\mathrm{o}}}-\frac{1}{T_{\mathrm{m}}^{\mathrm{o}}}=-\frac{R \overline{V_{c}}}{\Delta H_{\mathrm{mf}}^{\mathrm{o}} \overline{V_{\alpha}}} \cdot x \phi_{\alpha}^{2}$

where $T_{\mathrm{m}}^{\mathrm{o}}$ and $T_{\mathrm{mb}}^{\mathrm{o}}$ are the equilibrium melting points of the neat crystalline component (PCL) and the PCL/PC blend, respectively. The subscripts $\alpha$ and $c$ denote the amorphous and crystalline components. $R$ is the universal gas constant, $\Delta H_{\mathrm{m}}^{\mathrm{o}}$ is the molar heat of fusion for PCL $\left(3880 \mathrm{cal} \cdot \mathrm{mol}^{-1}\right)$ and $V$ is the molar volume $\left(V_{\mathrm{c}}\right.$ for $\mathrm{PCL}=105 \mathrm{~cm}^{3} \cdot \mathrm{mol}^{-1}, V_{\alpha}$ for $\mathrm{PC}=$ $\left.193.4 \mathrm{~cm}^{3} \cdot \mathrm{mol}^{-1}\right)$.

\subsection{Crystallization behaviour}

To be certain that the PCL/PC blends are not phaseseparated upon preparation, the isothermal crystallization kinetics were investigated by employing DSC and synchrotron SAXS [52, 53, 56, 57]. For neat PCL, the Avrami index $n$ was found to be between 3 and 3.7 and for the blends it varied between 3 and 4 , depending on the crystallization temperature used. This indicated that the nucleation mechanism changed 
from instantaneous $(n=3)$ to sporadic $(n=4)$ if spherulitic growth was assumed. When analyzing the variation of $n$ with composition and the variation of $n$ with increasing $T_{\mathrm{c}}$, the $n$ values in both cases exhibited an increase. This indicated a change in nucleation from instantaneous to sporadic. However, there was a general reduction in the values of $K$ both with increasing $T_{\mathrm{c}}$ and increasing PC content. This is due to the higher rigidity of $\mathrm{PC}$ in comparison with $\mathrm{PCL}$, which disturbed PCL's nucleation and molecular diffusion to the crystallizing front [53].

From the $n$ and $K$ values, the half-crystallization time (the time required to achieve 50\% relative crystallinity or the time that the sample needs to develop half the amount of crystals it will eventually produce) was calculated according to Equation (10):

$$
\tau_{50 \%}=\left(\frac{\ln 2}{k}\right)^{1 / n}
$$

The inverse of the experimentally determined halfcrystallization time $\left(1 / \tau_{50 \%}\right)$, is a quantity proportional to the overall crystallization rate (which includes both nucleation and growth). When the DSC results are coupled with the synchrotron findings, there existed a very strong parallel relationship between the overall rate of crystallization and the lamellar growth. The overall crystallization rate, $1 / \tau_{50 \%}$, as measured by DSC, and the lamellar growth, as monitored by synchrotron SAXS, decreased with increasing crystallization temperature and PC content $[53,56]$. This was due to the presence of $\mathrm{PC}$, that retarded both the overall crystallization rate and the lamellar growth of PCL, as well as the lower supercooling that slowed the crystallization process for all the composites [52].

\section{PCL/CNTs nanocomposites}

\subsection{Morphology}

Morphology characterization can answer many important questions about the distribution of nanotubes in a polymer matrix, the dispersion/agglomeration of the particles, and the interfacial interaction between the nanofiller and the polymer matrix [11]. Therefore, the visual aspects of morphology determination allow the investigator to hypothesize explanations concerning the observed property behaviour.

Extensive work has been conducted on PCL/ MWCNTs nanocomposites [40-43, 46, 59-68]. The samples were mostly prepared by melt blending, solution mixing and in situ polymerization. The melt blending method is generally considered less effective to disperse MWCNTs in PCL than the other techniques, due to primary MWCNT aggregates that could not be fully detached during melt processing. Solution mixing is a two-step sonication method in which the polymer is first dispersed in a solvent and then the MWCNTs are dispersed in the polymer solution, while in situ polymerization involves the polymerization of the monomer using a radical initiator, with the MWCNTs dispersed in the prepolymer through ultrasonication. The nanocomposites prepared through solution mixing and in situ polymerization showed a uniform dispersion of the MWCNTs in the polymer matrix, because the agglomerates could be broken down giving rise to better contact and interfacial interactions between PCL and the MWCNTs [43, 63]. However, the dispersed MWCNTs sometimes tended to reaggregate due to the van der Waals interactions among the MWCNTs, if the space between the dispersed MWCNTs was close enough. This tendency of reaggregation was more pronounced after stopping the ultrasonication and mechanical stirring. Several methods have been used to enhance the dispersion of MWCNTs into polymer matrices [43-45]. The methods commonly employed to improve dispersion include: (i) treatment of CNTs with inorganic solvents such as nitric acid $\left(\mathrm{HNO}_{3}\right)$, sulphuric acid $\left(\mathrm{H}_{2} \mathrm{SO}_{4}\right)$ and phosphoric acid $\left(\mathrm{H}_{3} \mathrm{PO}_{4}\right)$, in order to attach hydroxyl and carboxyl acid functional groups to the nanotubes, and (ii) the masterbatch approach, which is a direct encapsulation of the MWCNTs into a polymer matrix, and the subsequent release of the carbon nanotubes into the matrix polymer during mixing in the melt. The masterbatch method has received great interest from an industrial point of view, because it does not involve solvents that are harmful to the environment $[44,45,50]$. During the functionalization process, the use of strong acids could damage the nanotubes by shortening of the length or unzipping the MWCNTs [43].

In investigations of the effect of pristine and functionalized MWCNTs on the morphologies of PCL/ MWCNTs nanocomposites, the functionalized MWCNTs were found to be embedded in the PCL matrix and uniformly dispersed without apparent aggregation (Figure 2b). This was due to the formation of chemical bonds between the ester groups through a reaction between the carboxylic acid groups of PCL and the hydroxyl groups of functionalized MWCNTs. Some of the MWCNTs were emerging from the surface, but they were still surrounded by PCL, 


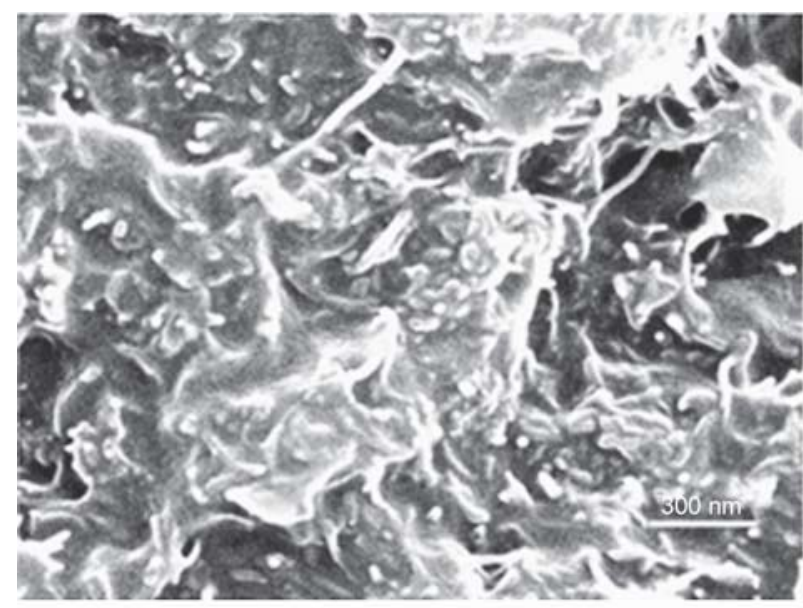

a)

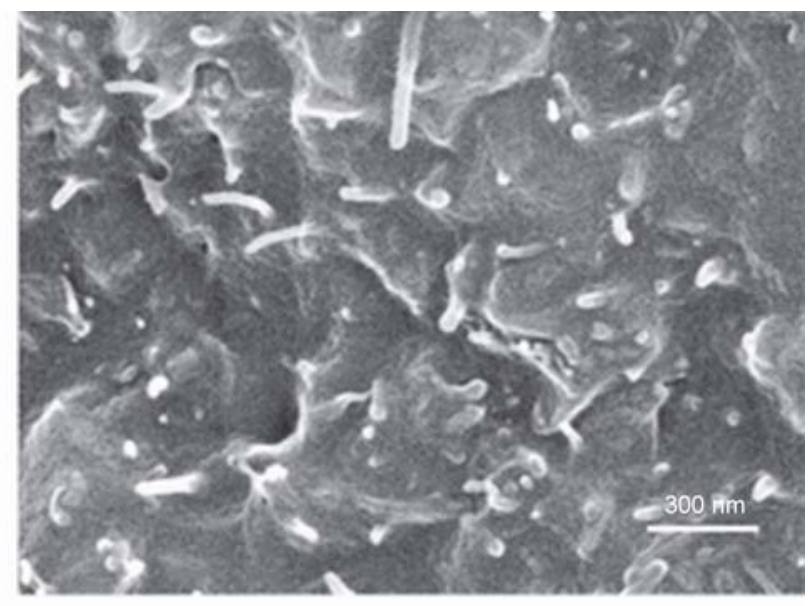

b)

Figure 2. SEM images of the fractured surfaces (a) $p$-MWNT (5 wt $\%) / \mathrm{PCL}$ and (b) $f$-MWNT (5 wt $\%$ )/PCL [64].

indicating good compatibility between the MWCNTs and the PCL matrix. On the other hand, the pristine MWCNTs (Figure 2a) were dispersed in the PCL matrix along with minor agglomerates due to the van der Waals interaction between the entangled carbon nanotubes [64].

Elsewhere in the literature [50], the authors prepared nanocomposites by melt blending PCL with a polycarbonate (PC)/multi-wall carbon nanotubes (MWCNTs) masterbatch in a twin screw extruder. Their results indicated the presence of two phases (PC-rich and PCL-rich phases), where a small amount of PCL chains were present in the PC-rich phase, and can plasticize the PC component, such that it can crystallize. The PCL-rich phase contained only a small amount of PC chains, such that changes in the $T_{\mathrm{g}}$ of the PCL phase were much smaller than those predicted by the Fox equation. Due to the partial miscibility and the establishment of PC-rich and PCL-rich phases, a fair number of MWCNTs diffused from the PCrich phase to the PCL-rich phase, but their diffusion depended on the masterbatch content in the blend.

\subsection{Mechanical and thermo-mechanical properties}

Mechanical performance of polymer nanocomposites is dependent upon the interfacial interaction between the nanofiller and the polymer matrix, chain stiffness, and the crystallinity of the polymer in the nanocomposite. This implies that to utilize the reinforcing capability of carbon nanotubes and to maximize the mechanical properties of the nanocomposites, strong interfacial bonding is necessary. The extent of interaction depends on how well the filler is dispersed in the matrix [27]. Several authors evaluated the mechanical and thermo-mechanical performance of pristine and functionalized MWCNTs ( $f$-MWCNTs) in PCL nanocomposites [39, 59, 60, 62, 68]. Generally, non-functionalized MWCNTs existed as agglomerates, because of the van der Waals forces and electrostatic interactions between the carbon nanotubes. The carbon nanotube agglomerates act as stress concentration points in the polymer matrix and can, in some cases, reduce the mechanical properties of the original polymer [39]. Functionalized MWCNTs nanocomposites gave much better mechanical properties than non-functionalized MWCNTs nanocomposites, which was ascribed to a better dispersion of the functionalized MWCNTs in the PCL matrix compared to the non-functionalized MWCNTs [59, $60,68]$. The mechanical properties such as tensile modulus, compressive modulus, tensile strength, storage modulus and elastic modulus increased with increasing MWCNTs content up to $0.5 \mathrm{wt} \%$. However, the properties were more improved for the $f$-MWCNTs than for the pristine MWCNTs nanocomposites $[41,62,68]$. The improvement of these properties was related to the better dispersion of the $f$-MWCNTs in the polymer matrix that provided more uniform stress distribution, minimized the presence of stress-concentration centres, and increased the interfacial area for stress transfer from the polymer matrix to the MWCNTs $[39,59,60,62,68]$. Increasing the MWCNTs content above $0.5 \mathrm{wt} \%$ (especially for pristine MWCNTs) resulted in a decline in the mechanical properties of the nanocomposites. This was due to the formation of MWCNTs aggregates, which led to poor dispersion in the polymer matrix [41]. 


\subsection{Nucleation and crystallization behaviour}

The nucleation and crystallization behaviour of polymer nanocomposites is very important, because it affects not only the crystalline structure and morphology of semi-crystalline polymers, but also the final physical properties of the material. In previous research [46, 60, 64, 67-69], different functional groups such as $N$-methylpyrrolidine, carboxyl and hydroxyl, urethane, phenylmethanol, primary amine groups and 2-hydroxyethylbenzocyclobutene were used to functionalize MWCNTs. In some cases, the MWCNTs were not modified [40, 50, 66, 69]. In order to evaluate the efficiency of the MWCNTs as nucleating agents, it is necessary to compare their effect with that of the PCL self-nuclei or self-seeds. Self-nucleation (SN) experiments deal with the dependence of the melting temperature or self-nucleation temperature $\left(T_{\mathrm{S}}\right)$ on the subsequent crystallization process. According to Fillon et al. [70], three different domains can be identified. Domain $I$ is when the $T_{\mathrm{s}}$ temperature is high enough to melt all the crystals and destroy the crystalline memory. Domain II is when lower $T_{\mathrm{s}}$ values will partially melt the crystals or leave some residual crystalline memory that can selfnucleate the material during cooling from $T_{\mathrm{s}}$. Domain III is when lower $T_{\mathrm{s}}$ temperatures can only partially melt the material, and unmolten crystals can anneal during the time the sample stays at $T_{\mathrm{s}}$ (usually $5 \mathrm{~min}$ ), while the molten material can self-nucleate during cooling from $T_{\mathrm{s}}$. The self-nucleation temperature that originates the largest amount of self-nuclei is the lowest temperature belonging to Domain II. This temperature is called the ideal $T_{\mathrm{s}}\left(T_{\mathrm{s}, \text { ideal }}\right)$. It is expected that the $T_{\mathrm{c}}$ values after $\mathrm{SN}$ at $T_{\mathrm{s} \text {,ideal }}$ are the highest temperatures for the crystallization under non-isothermal conditions for a polymer. In fact, Fillon et al. [70] used such values as a reference to calculate the efficiency of a nucleating agent. The efficiency of the MWCNTs as nucleating agents for PCL was calculated according to Equation (11), which was proposed by Fillon et al. [71]:

$$
N E=\frac{T_{\mathrm{c}, \mathrm{NA}}-T_{\mathrm{c}, \mathrm{PCL}}}{T_{\mathrm{c}, \max \mathrm{A}}-T_{\mathrm{c}, \mathrm{PCL}}} \cdot 100
$$

where $T_{\mathrm{c}, \mathrm{NA}}$ is the peak $T_{\mathrm{c}}$ value determined from a non-isothermal DSC cooling run for a sample of the polymer with the nucleating agent (NA), $T_{\mathrm{c}, \mathrm{PCL}}$ is the peak $T_{\mathrm{c}}$ value for neat PCL after its crystalline history has been erased (also determined from a non-isothermal DSC cooling scan), and $T_{\mathrm{c}, \max }$ is the maximum peak crystallization temperature determined after neat PCL has been self-nucleated at the ideal selfnucleation temperature or $T_{\mathrm{s}, \text { ideal }}$ (i.e., the self-nucleation temperature that produces maximum self-nucleation without any annealing) [71, 72].

Müller and coworkers [66, 69] first described supernucleation effects for PCL/CNT nanocomposites. Supernucleation refers to the nucleation action that is better than that provided by the polymer's own crystals. A characteristic of this behaviour is a large increase in $T_{\mathrm{c}}$. Some authors did, however, encounter antinucleation effects when the interaction between the CNTs' surfaces and the polymer was very poor [46]. Figure 3 summarizes the shifts in non-isothermal crystallization temperatures from that of neat PCL after introduction of CNTs, and the reasons for the differences observed in this figure are discussed in the next paragraphs.

Trujillo et al. [66] investigated the nucleation behaviour of simple melt mixed, untreated PCL/MWCNTs nanocomposites, and reported for the first time a supernucleation effect in a well dispersed melt mixed system. This result indicated that the CNTs supernucleation could be dominated by (i) the strong interaction between the polymer and the MWCNTs and (ii) the dispersion quality of the blend. A similar or better supernucleation effect was reported when PCL was blended with PCL grafted MWCNTs (MWCNTs-g-PCL) [69]. The supernucleation effect of the MWCNTs was the result of an excellent dispersion of the MWCNTs in the polymer matrix. However, the improvement in the dispersion with the modification of MWCNTs approach led to a decrease of its

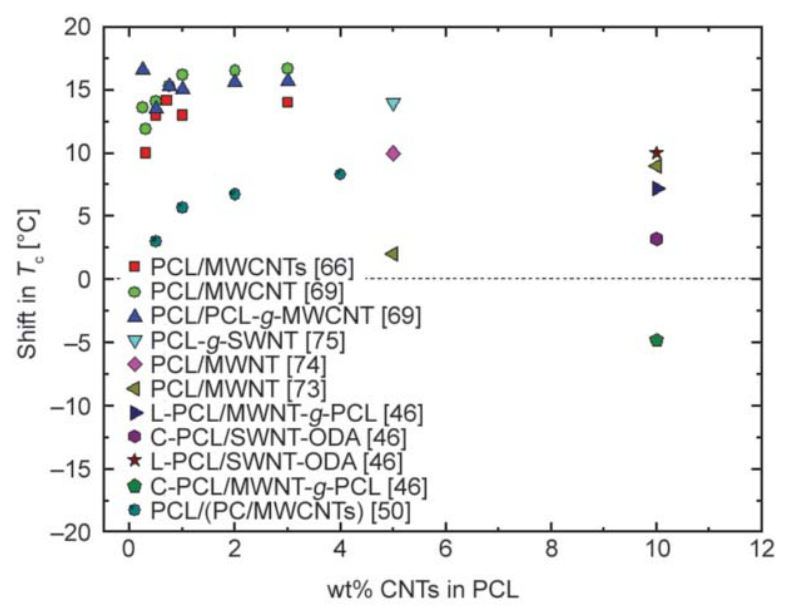

Figure 3. Crystallization temperature $\left(T_{\mathrm{c}}\right)$ shift (difference between the $T_{\mathrm{c}}$ value of neat PCL and the $T_{\mathrm{c}}$ value of the PCL with CNTs) for different PCL/CNT systems reported in the literature. 
nucleation capacity, as a result of the agents introduced. Sanchez-Garcia et al. [73] prepared PCL/ MWCNT nanocomposites by solution blending and obtained an increase in $T_{\mathrm{c}}$ of the PCL of only $2{ }^{\circ} \mathrm{C}$ for $5 \mathrm{wt} \% \mathrm{CNT}$ content. When they increased the MWNT content to $10 \mathrm{wt} \%$, they observed a maximum increase in $T_{\mathrm{c}}$ of $9^{\circ} \mathrm{C}$. Wu et al. [74] obtained $T_{\mathrm{c}}$ shifts of up to $10^{\circ} \mathrm{C}$ in nanocomposites of PCL with $5 \mathrm{wt} \%$ functionalized MWNTs (the nanocomposites were prepared by a 'grafting to' technique during melt blending). On the other hand, Mitchell and co-workers [75] prepared PCL- $g$-SWNT nanocomposites with a 'grafting from' method and were able to observe a maximum increase in $T_{\mathrm{c}}$ of $14^{\circ} \mathrm{C}$ with a $5 \mathrm{wt} \%$ MWNT content. Gumede et al. [50] prepared PCL/(PC/MWCNTs) nanocomposites by melt blending and obtained an increase in Tc of the PCL up to $1 \mathrm{wt} \%$ MWCNTs content. At MWCNT concentrations above $1 \mathrm{wt} \%$, the increase was slow due to (i) limited phase mixing between the PC-rich and the PCL-rich phases, and (ii) an agglomeration of MWCNTs and PC crystallization.

Not all the literature reported increases in $T_{\mathrm{c}}$ for the PCL/CNT nanocomposites, because the efficiency of a nucleating agent depends on, among other factors, the interaction between the polymer and the CNT surface, and the quality of the dispersion and distribution of the particles. Pérez and co-workers [46] reported that MWCNTs, functionalized with 2hydroxyethyl benzocyclobutene (BCB-EO) through a Diels-Alder cycloaddition reaction, nucleated linear PCL (L-PCL), but showed an antinucleation effect in cyclic PCL (C-PCL). This was due to the reduced diffusion of C-PCL induced by the threading effect induced by the L-PCL molecules grafted to the MWCNTs, which opposed the nucleating effect of the MWCNTs.

Crystallinity and crystalline morphology have an influence on the strength and mechanical properties of a polymer nanocomposite, and it is therefore important to understand the influence of the other component in the nanocomposite on the crystallization behaviour of a particular component. To describe the crystallization kinetics, the overall crystallization rate, $1 / \tau_{50 \%}$ (which includes both primary nucleation and growth kinetics components) is expressed as the inverse of the experimentally determined half-crystallization time and depends on isothermal crystallization temperatures. Table 1 shows crystallization temperature ranges for neat PCL and different PCL/ CNT systems reported in the literature. In most of the kinetic studies $[50,66,69]$ on the crystallization of PCL/CNTs nanocomposites there were three general observations: (i) The crystallization temperature range for neat PCL was lower than those for the nanocomposites. This was an indication that the supercooling needed for the development of isothermal crystallization in the nanocomposites is much lower than that for neat PCL in view of the nucleation effect that they cause on the PCL matrix; (ii) The overall crystallization rate increased with MWCNTs loading for the systems explored, which was probably due to the nucleation effect that accelerated the primary nucleation and contributed to increasing the overall crystallization kinetics; (iii) The temperature dependence of the overall crystallization rate was not the same $[46,50,66,69]$. However, in study [46] the crystallization temperature range for C-PCL was higher than that of the C-PCL/MWNT-g-PCL nanocomposite, and the nanocomposite exhibited a decrease in overall crystallization rate compared to C-PCL. This was because of the antinucleation effect caused by the MWNT-g-PCL on C-PCL (caused by the threading effects of the grafted linear PCL chains and the CPCL chains).

The influence of MWCNTs on the crystallinity of a polymeric matrix can vary, depending on the polymer/MWCNTs interaction and the nanofiller dispersion achieved. Different trends were reported in terms of evaluating the percentage crystallinity of PCL/MWCNTs nanocomposites, amongst others an increase [66], a decrease [50, 60] and no change [46] after the addition of MWCNTs. The increase in crystallinity was attributed to the excellent dispersion

Table 1. Crystallization temperature range for neat PCL and different PCL/CNT systems reported in the literature.

\begin{tabular}{|c|c|c|c|c|}
\hline Sample & & & & \\
\hline Neat PCL & $\begin{array}{l}{ }^{*} 33.0-40.5[46] \\
{ }^{* *} 43.0-46.5[46]\end{array}$ & $45.0-49.5[66]$ & $35.0-44.0$ [69] & $41.0-50.0[50]$ \\
\hline Nanocomposites & $\begin{array}{r}{ }^{*} 36.5-40.5[46] \\
{ }^{* *} 39.0-46.5[46]\end{array}$ & $49.0-54.5[66]$ & $48.0-53.0$ [69] & $42.0-54.0[50]$ \\
\hline
\end{tabular}

${ }^{*} \mathrm{~L}-\mathrm{PCL},{ }^{* *} \mathrm{C}-\mathrm{PCL}$ 
and nucleating power of the MWCNTs, and the decrease to steric restrictions between the polymer chains and the MWCNTs that limited chain diffusion during crystallization.

The data obtained during the isothermal crystallization experiments were analyzed employing the Avrami equation, which is expressed in Equation (12) [76]:

$$
1-V_{\mathrm{c}}\left(t-t_{0}\right)=\exp \left(-K\left(t-t_{0}\right)^{n}\right)
$$

where $t$ is the experimental time, $t_{0}$ is the induction time, $V_{\mathrm{c}}$ is the relative volumetric transformed fraction, $n$ is the Avrami index, and $K$ is the overall crystallization rate constant. The Avrami index $n$, which is obtained from the slope of the linear fit in Equation (3), represents the order of the crystallization kinetics and depends on the dimensionality of the crystalline superstructure and on their nucleation kinetics $[76,77]$. Generally, neat PCL revealed Avrami index values of approximately $n=3$. This indicates that (i) the crystal geometry is spherulitic and follows an athermal nucleation which leads to spherulites of roughly the same size during isothermal crystallization, and that (ii) the nucleation is very fast (instantaneous), and the nucleation starts almost immediately after the isothermal crystallization temperature was reached [47, 66, 69]. Trujillo et al. [66] reported lower Avrami index values (approximately $n=2$ ) for PCL/CNT nanocomposite systems compared to the $n=3$ for neat PCL, corresponding to the formation of axialites. This indicates that the growth of the polymer crystals was affected by the dense nucleation on the MWCNTs surfaces, thereby decreasing the dimensions of the polymer crystals. Gumede and coworkers [50] reported values higher than 3 for the $\mathrm{PCL} /(\mathrm{PC} / \mathrm{MWCNTs})$ nanocomposites, which was unexpected because it was reported that MWCNTs are effective in nucleating PCL. In some cases, the Avrami index values showed slight variations for both neat PCL and the nanocomposites in the range of 1.4 to 1.8. The slight variation of $\mathrm{n}$ indicates that the crystallization mechanism may not change within the investigated crystallization temperature range, irrespective of the content of the MWCNTs [68]. An increase in $n$ values was also reported [46], as nucleation tends to be more sporadic with increasing temperature. The Avrami index values were within 2.5-3, indicating instantaneous spherulites were formed. At low $T_{\mathrm{c}}$ values, the Avrami index approached 2 (corresponding to axialites) indicating that nucleation densities are too high and early impingement prevented superstructures from developing full tridimensional spherulites. However, in the case of C-PCL/MWNT-g-PCL, the effect caused a relatively more sporadic nucleation as Avrami indices were between 3.5 and 4 at high $T_{\mathrm{c}}$ temperatures. Since the unit of $K$ (intercept of the linear fit in Equation (3)) is $\min ^{-n}$ and $n$ is not constant, it is difficult to compare the crystallization rate directly from the values of $K$. However, the values of $K^{1 / n}$ display a similar trend to $1 / \tau_{50 \%}$, since $K_{1 / \mathrm{n}}$ is also related to the overall crystallization kinetics.

In addition to the use of the Avrami equation, many researchers employed nucleation and growth theories to fit the crystallization kinetics data. The most widely employed approach is the Lauritzen and Hoffman (LH) theory, originally derived for secondary nucleation, and extended to nucleation and growth DSC data, in the expression given by Equation (13) [78]:

$$
\frac{1}{\tau_{50 \%}}(T)=\frac{1}{\tau_{0}} \exp \left(\frac{-U^{*}}{R\left(T_{\mathrm{c}}-T_{\infty}\right)}\right) \exp \left(\frac{-K_{\mathrm{g}}^{\tau}}{T_{\mathrm{c}} \Delta T_{\mathrm{f}}}\right)
$$

where $1 / \tau_{50 \%}$ is the inverse of the experimental halfcrystallization time (obtained by DSC isothermal experiments), $1 / \tau_{0}$ is a pre-exponential factor that includes nucleation and growth, $U^{*}$ is the activation energy for the transport of the chains to the growing front (a value of $1500 \mathrm{cal} \cdot \mathrm{mol}^{-1}$ is usually employed), $R$ is the gas constant, $T_{\mathrm{c}}$ is the isothermal crystallization temperature $[\mathrm{K}], T_{\infty}$ is the temperature at which chain mobility ceases (usually taken as $T_{\mathrm{g}}-30 \mathrm{~K}$ ), and $\Delta T$ is the supercooling $\left(T_{\mathrm{m}}^{\mathrm{o}}-T_{\mathrm{c}}\right)$, with $T_{\mathrm{m}}^{\mathrm{o}}$ as the equilibrium melting temperature. The correction factor $f$ is a temperature correction term equal to $2 T_{\mathrm{c}} /\left(T_{\mathrm{c}}+T_{\mathrm{m}}^{\mathrm{o}}\right)$, and $K_{\mathrm{g}}^{\tau}$ is a constant related to the energy barrier for crystallization and growth. If the crystallization rate is approximated to experimentally determined values of the inverse of half crystallization times $\left(1 / \tau_{50 \%}\right)$, then $K_{\mathrm{g}}^{\tau}$ values are proportional to the energy barrier for overall crystallization. The value of $K_{\mathrm{g}}^{\tau}$ is given by Equation (14) according to the Lauritzen and Hoffman theory:

$K_{\mathrm{g}}^{\tau}=\frac{j b_{0} \sigma \sigma_{\mathrm{e}} T_{\mathrm{m}}^{0}}{k \Delta h_{f}}$

where $b_{0}$ is the width of the chain, $\sigma$ is the lateral surface free energy, $\sigma_{\mathrm{e}}$ is the fold surface free energy, $T_{\mathrm{m}}^{0}$ is the equilibrium melting temperature $[\mathrm{K}], k$ is the Boltzmann constant and $\Delta h_{\mathrm{f}}$ is the heat of fusion 
of a perfect crystal. The parameter $j$ is determined by the crystallization regime and is equal to 4 for regime I and III, and equal to 2 for regime II. The LauritzenHoffman theory analyzes the growth data according to competition between the rate of deposition of secondary nuclei (i) and the rate of lateral surface spreading $(g)$, resulting in three different regimes. Regime I occurs when $i \ll g$ and may be found at very low supercoolings; in regime II, $i$ is of the order of $g$ and occurs at moderate supercoolings; in regime III, $i>g$ and is found at very high supercoolings. From the values of $K_{\mathrm{g}}^{\tau}$, the product $\sigma \sigma_{\mathrm{e}}$ is obtained from Equation (14). Equations (15) and (16) allow the calculation of $\sigma$ (and therefore $\sigma_{\mathrm{e}}$ ) and $q$, the work done by the chain to form a fold:

$$
\sigma=0.1 \Delta h_{\mathrm{f}} \sqrt{a_{0} b_{0}}
$$

$q=2 a_{0} b_{0} \sigma_{\mathrm{e}}$

where $a_{0} b_{0}$ is the cross-sectional area of the chain. To obtain the parameters of the LH theory, the following values were used: $T_{\mathrm{g}}=213 \mathrm{~K}, T_{\mathrm{g}}-30 \mathrm{~K}$, $\Delta H=163 \mathrm{~J} \cdot \mathrm{g}^{-1}, a_{0}=4.52 \AA, b_{0}=4.12 \AA, p_{\mathrm{c}}=$ $1.1 \mathrm{~g} \cdot \mathrm{cm}^{-3}, U^{*}=1500 \mathrm{cal} \cdot \mathrm{mol}^{-1}$. According to the literature [78], the $K_{\mathrm{g}}^{\tau}$ values are lower for the nanocomposites than for neat PCL. This result was interpreted by considering that a supernucleation effect contributed to decreasing the energy barrier for overall crystallization (which includes both nucleation and growth) and decreased the fold surface free energy $\left(\sigma_{e}\right)$ and the work needed for the chains to fold $(q)$. It was found that above $0.5 \mathrm{wt} \%$ MWCNTs loading [66], the supernucleation effect was so large that a transition to Regime III occurred, since nucleation was much faster than the spreading rate. However, some studies reported only Regime II for the nanocomposites, indicating that the nucleation was not so fast due to the moderate supercoolings and interaction between the polymer and the MWCNTs $[79,80]$.

\subsection{Conductivity}

Heat dissipation in modern electronic devices require interface materials with high electrical and thermal conductivities. Nanocomposites made up of polymer matrices and carbon nanotubes have been investigated with the aim of utilizing the good thermal and electrical properties of carbon nanotubes. Currently, the proposed applications for PCL/CNTs nanocomposites include vapour sensors, electromagnetic interference shielding and structural biomaterials for tissue engineering when electro-spun into membranes. A low electrical percolation threshold and good electrical conductivity are the critical properties required. It is important to note that electrical and thermal conductivities occur according to different mechanisms. The mechanism of thermal energy transport in CNTs is perceived to take place through phonon conductivity, and it preferably occurs in the crystalline parts in the bulk of the polymer, and to a smaller extent at the points of contact with the CNTs. Phonons transfer heat energy through interactions with each other and with subatomic particles. On the other hand, the mechanism of electrical energy transport in CNTs is dominated by the tunneling distances at the nanotube-nanotube contacts [40-42, 49, 64]. The type of processing method, dispersion and concentration of the CNTs play a significant role in their electrical conductivities.

Several studies investigated (i) the electrical conductivities of pristine and functionalized MWCNTs, (ii) the percolation threshold in PCL nanocomposites, and (iii) the dependence of electrical and thermal conductivities on the degree of crystallinity of PCL [40-42, 50, 64, 49, 81, 82]. In general, irrespective of the reported methods of PCL/MWCNTs nanocomposites preparation, the percolation threshold of the nanocomposites was less than $1.0 \mathrm{wt} \%$ in most cases (Table 2). This indicated that the MWCNTs were fairly well dispersed in the polymer matrix and could connect with each other, and subsequently form an

Table 2. A comparative study of PCL/MWCNTs nanocomposites.

\begin{tabular}{|l|l|c|c|c|}
\hline \multicolumn{1}{|c|}{ Functionalization technique } & \multicolumn{1}{c|}{ Dispersion technique } & MWCNTs content & Percolation threshold & Reference \\
\hline No MWCNTs modification & melt-mixing & $0.2-0.5 \mathrm{wt} \%$ & $0.20 \mathrm{wt} \%$ & {$[40]$} \\
\hline No MWCNTs modification & melt-mixing & $0.05-5.0 \mathrm{wt} \%$ & $0.30 \mathrm{wt} \%$ & {$[41]$} \\
\hline No MWCNTs modification & melt-mixing & $0.5 \mathrm{wt} \%$ & $2.00 \mathrm{wt} \%$ & {$[42]$} \\
\hline Nitric acid-treatment & in situ polymerization & $0.5-5.0 \mathrm{wt} \%$ & - & {$[64]$} \\
\hline No MWCNTs modification & melt blending & $0.35-7.0 \mathrm{wt} \%$ & $0.14 \mathrm{wt} \%$ & {$[49]$} \\
\hline PC/MWCNTs masterbatch & melt blending & $0.5-4.0 \mathrm{wt} \%$ & $0.5-1.0 \mathrm{wt} \%$ & {$[50]$} \\
\hline
\end{tabular}


interconnecting conductive pathway. The electrical conductivity values increased by more than one order of magnitude. The increase in the electrical conductivity with increasing crystallinity can be explained by the reduction of the nanotube-nanotube distances in their contact regions, which suggested an enhancement in the electron transport and a reduction in ion mobility in the crystalline phase [40]. Both the pristine and functionalized nanocomposites showed good electrical conductivity at low MWCNTs contents, which is related to the formation of a conductive nanotube network. However, the electrical conductivity values of the nanocomposites with pristine MWCNTs was higher than those of the nanocomposites with functionalized MWCNTs. This is due to the acid treatment in the functionalized MWCNTs, which usually destroys the $\pi$-network in the carbon nanotubes [64]. The thermal conductivities of the $\mathrm{PCL} /(\mathrm{PC} / \mathrm{MWCNTs}$ ) nanocomposites (with $4 \mathrm{wt} \%$ MWCNTs content) increased by $20 \%$ in comparison to that of the neat material [50]. This is because the thermal conductivity of carbon nanotubes ranges between 650 and $10000 \mathrm{~W} \cdot \mathrm{m} \cdot \mathrm{K}^{-1}$, and the thermal conductivity of a typical polymer ranges between 0.1 and $0.3 \mathrm{~W} \cdot \mathrm{m} \cdot \mathrm{K}^{-1}$ [39], and therefore the improvement in the thermal conductivity is most probably caused by the increasing numbers of high thermal conductive MWCNTs in the nanocomposites. Since the MWCNTs were fairly well dispersed in the PCL/ PC blend (although there were pockets where the MWCNTs were concentrated), the MWCNTs were positioned closer to each other as the MWCNTs content increased, which gave rise to more effective transport of the phonons through the nanocomposite, and which improved the transportation of heat by high frequency phonon vibration, leading to higher thermal conductivities.

\subsection{Rheological properties}

Rheology is the study of the flow behaviour of a material under conditions in which they flow rather than deform. The study of the rheological response of CNT/ polymer nanocomposites has both practical importance related to composite processing and scientific importance as a probe of the composite dynamics and microstructure. The rheological properties of CNT/ polymer nanocomposites depend on factors such as aspect ratio, dispersion, polymer molecular weight, the interfacial interaction between the polymer and filler, and the characteristics of the filler loading [43].
The variations of viscosity and storage modulus of composites as a function of frequency are two commonly used techniques to characterize the rheological properties of CNT/polymer nanocomposites.

The complex viscositiy $\left(\eta^{*}\right)$ at low frequencies increased as the MWNT content increased for PMWNT/PCL and A-MWNT/PCL. The $\eta^{*}$ of PMWNT/PCL and A-MWNT/PCL showed Newtonian behaviour for MWCNT contents less than $2 \mathrm{wt} \%$, while those of higher than $2 \mathrm{wt} \%$ MWCNTs showed profound shear-thinning behaviour. This viscosity behaviour indicated that a percolation threshold, which represents a starting MWCNT content for a three-dimensional network, was $2 \mathrm{wt} \%$ for both the P-MWNT/PCL and A-MWNT/PCL [64].

Pötschke et al. [42] prepared composites of PCL and $0.5 \mathrm{wt} \%$ MWCNTs at different rotation speeds by melt-mixing in a conical twin-screw micro-compounder. The results for the composite produced at the lowest mixing speed $(25 \mathrm{rpm})$ and having the highest agglomerate ratio were similar to those of neat PCL, but at low frequencies there was already a deviation towards higher values. The two composites produced at 50 and $75 \mathrm{rpm}$ (showing decreased agglomerate area ratios) showed a pronounced increase in complex viscosity and storage modulus at all frequencies, but especially at low frequencies. These changes implied the better development of a combined filler-polymer network. However, at higher rotation speeds (above $75 \mathrm{rpm}$ ), a decrease in the complex viscosity and storage modulus at low frequencies was reported, which was explained through an overlapping influence of nanotube shortening during the mixing process at the corresponding higher shear stresses. The effects were also related to the dispersion and nanotube shortening, but a third possible influence, namely PCL degradation at higher mixing speeds, could be excluded.

\section{PBS/CNTs nanocomposites}

\subsection{Morphology}

In the reported research, multi-walled carbon nanotubes (MWCNTs)/polybutylene succinate (PBS) nanocomposites were prepared by two frequently used methods, melt and solution mixing. The state of dispersion of MWCNTs depended on the mixing method, modification and concentration of MWCNTs in the nanocomposites.

Nanocomposites prepared by melt blending resulted in MWCNTs aggregation, which is inefficient in 
dispersing the aggregates into individual MWCNTs, despite the large shear forces applied during mixing [83-87]. In the case of nanocomposites prepared through solution mixing, no apparent aggregation was reported. This is due to the use of ultrasonication that is able to disrupt nanotube aggregation, giving rise to better contact between PBS and the MWCNTs [88]. Several chemical methods have been reported for the functionalization of MWCNTs, such as (i) the use of $N, N^{\prime}$-dicyclohexylcarbodiimide (DCC) to introduce a long alkyl chain onto the MWCNTs, and (ii) surface wrapping of poly(sodium 4-styrenesulfonate) (PSS) with the aid of ultrasound [47, 88]. In these studies, the MWCNTs were well dispersed in the PBS matrix and showed better interfacial adhesion with the PBS phase than with each other. This is due to $\pi-\pi$ interactions between the benzene rings, and between the long alkyl chain groups and the graphite rings of the MWCNTs.

The concentration of the MWCNTs was found to have an influence on the state of dispersion and distribution in the polymer matrix. Some authors studied the effect of melt-mixed MWCNTs on the morphology of the PBS/MWCNTs nanocomposites [8385]. Their results indicated that at low MWCNTs content (i.e., $1 \mathrm{wt} \%$ ), the carbon nanotubes were well dispersed and embedded in the PBS matrix. However, at high MWCNTs loadings (i.e., $3 \mathrm{wt} \%$ ), the carbon nanotubes were poorly dispersed as aggregates. It is well known that agglomeration of filler nanoparticles increases with increasing filler content. This is because the nanotubes are closer to each other as the content of the nanotubes increases, and agglomeration occurs due to the Van der Waals interactions between the MWCNTs. It is difficult separating these MWCNTs during melt processing, even when the MWCNTs are modified. MWCNTs were also functionalized by surface wrapping of PSS with the aid of ultrasound, and the nanocomposites were prepared by solution mixing [88]. In this case, the carbon nanotubes were uniformly dispersed in the PBS matrix. No obvious aggregation was reported for all the nanocomposites.

\subsection{Mechanical and thermo-mechanical properties}

Several factors, such as dispersion, distribution and matrix-CNTs interfacial adhesion, influence the mechanical and thermo-mechanical properties of polymer nanocomposites $[83,86]$. Tensile testing and dynamic mechanical analysis (DMA) were employed to study the mechanical and thermo-mechanical properties of the nanocomposites. The nanocomposite preparation methods, in most cases either melt-mixing or solution-blending, led to different properties of the materials. For instance, PBS/MWCNTs nanocomposites prepared by solution mixing exhibited better mechanical properties, such as higher tensile strength and storage modulus, than the melt-mixed nanocomposites. This was due to the better dispersion of the MWCNTs in the PBS matrix for the solution mixed samples [88].

The effect of pristine and functionalized MWCNTs on the mechanical and thermo-mechanical properties of the PBS/CNTs nanocomposites were investigated in a number of studies $[33,47,83,84,86,88,89]$. The carbon nanotubes were mostly functionalized using (i) acid solution followed by grafting MWCNTs with polyetheramines, (ii) $N, N^{\prime}$-dicyclohexylcarbodiimide (DCC) dehydrating agents, (iii) nitric acid, and (iv) surface wrapping of MWCNTs with PSS with the aid of ultrasound. The nanocomposites containing functionalized MWCNTs exhibited an increase in the storage modulus and Young's modulus with increasing MWCNTs content, while the elongation at break for the nanocomposite samples was smaller than that of neat PBS. This was attributed to the well dispersed carbon nanotubes in the PBS matrix and the good interaction between the components in the nanocomposites, that resulted in more uniform stress distribution and minimization of the presence of stress-concentration centres. This further implied that the nanotubes could enhance the rigidity of the nanocomposites, because reinforcement by incorporation of MWCNTs causes a loss in flexibility $[33,47,83,88]$. For nanocomposites containing pristine MWCNTs, the storage modulus, loss modulus, and tensile strength initially increased with increasing MWCNTs contents, but then decreased for MWCNTs contents above $3 \mathrm{wt} \%$. This was attributed to the significant aggregation of the pristine MWCNTs that prevented efficient load transfer to the polymer matrix. The significant improvement in mechanical properties at lower MWCNT contents was attributed to the incorporation of rigid MWCNTs into the relatively soft PBS matrix that caused a reinforcement effect [86]. Elsewhere in the literature [88], the authors investigated the effects of different carbonaceous nanoparticle types such as carbon nanotubes (CNT), carbon black $(\mathrm{CB})$, and fullerene $(\mathrm{F})$ on the dynamic 
mechanical properties of PBS. Their results indicated that all the nanocomposites exhibited higher storage modulus with respect to neat PBS below the glass transition temperature. This was attributed to the reinforcement effect of the presence of rigid carbon nanoparticles and the good interaction between PBS and nanofillers, leading to a prominent improvement in the stiffness of the PBS matrix. The modulus of $\mathrm{PBS} / 1 \mathrm{wt} \%$ CNT nanocomposite was the highest, because of the higher interfacial area between CNT and the PBS. However, the storage modulus leveled off at temperatures above $50^{\circ} \mathrm{C}$ for both neat PBS and its nanocomposites, indicating that the effect of the nanofiller incorporation became negligible, and the rigidity of the nanocomposites was matrix-dependent. The glass transition temperature of the nanocomposites did not change with respect to PBS by the addition of different carbonaceous nanoparticles. The results indicated that the molecular movements or segmental motions of the PBS matrix were not significantly affected by the incorporation of the nanofillers.

\subsection{Melting and crystallization behaviour}

The melting and crystallization behaviour of polymer nanocomposites has an influence on the strength and mechanical properties of the final product. It is therefore important to understand the influence of the nanofiller in the nanocomposite on the crystallization behaviour of the polymer. A number of studies investigated the melting, nucleation, and crystallization behaviour of PBS/MWCNTs nanocomposites by DSC and polarized light optical microscopy (PLOM) [47, 84-86, 88-91]. Generally, double melting peaks were reported for all the PBS/MWCNTs nanocomposites, associated with the partial melting, recrystallization, and re-melting of the PBS crystallites. The main peak remained at the same temperature as the melting of neat PBS, but the small peak shifted towards a lower temperature with increasing MWCNTs content. The main peak was attributed to the melting of larger, more perfect crystals that was not affected by the presence of MWCNTs, while the small peak was ascribed to the melting of unstable crystals formed at a higher temperature. This was due to the nucleating effect of the MWCNTs that reduced the ability of the PBS chains to be fully incorporated into the growing crystalline lamellae.

In most cases, the crystallization temperature, $T_{\mathrm{c}}$, of all the PBS/MWCNTs nanocomposites was higher than that of neat PBS, and increased with increasing MWCNTs content. This was attributed to the nucleating effect of the MWCNTs on PBS crystallization that improved the crystallizability of the PBS. However, with an increase in MWCNTs content above $0.5 \mathrm{wt} \%$, the Tc increased only slowly, indicating a saturation in the nucleation effect at higher MWCNTs contents [47, 84, 86, 88-90]. In order to visualize the nucleating ability of MWCNTs on the crystallization of PBS, the spherulitic morphology of neat PBS and its nanocomposites was investigated (Figure 4). Neat PBS showed well-developed, large Maltese-cross pattern spherulites with clear boundaries. However, with increasing MWCNTs content, the sizes of the spherulites decreased while the number of spherulites gradually increased. This was an indication of the nucleating effect of the MWCNTs on the PBS crystallization that hindered the growth of the PBS crystals through obstruction of the folding of the PBS chains during the crystallization process. At high MWCNTs content the spherulites were not well-developed, imperfect and grew rapidly. The presence of MWCNTs caused impingement and restricted further growth of the spherulites. This was due to the formation of large numbers of nucleation sites at high MWCNTs contents $[84,85,88$, 90, 91].

Since the presence of CNTs had a large influence on the crystallization behaviour of PBS, it was necessary to further explore the crystallization kinetics of the PBS/CNTs nanocomposites. Both the isothermal $[85,90]$ and non-isothermal $[87,91]$ crystallization kinetics of neat PBS and the nanocomposites were explored. For non-isothermal crystallization kinetics, several different kinetic models were employed [87, 91]. The Avrami equation (as described in section 3.3) was used to describe the isothermal crystallization. Irrespective of the nanocomposite preparation method, the type of CNTs (single or multi walled), or the crystallization temperature range used, the Avrami index values for both neat PBS and the PBS/CNTs nanocomposites were approximately 3 . This indicated that although the CNTs provided additional nucleation sites and enhanced the nuclei density, the mechanism of crystal growth for PBS did not change with the addition of MWCNTs. In contrast, the Avrami index values for the PBS/MWCNTs nanocomposites $(n=2)$ were lower than that of neat PBS $(n=3)$. This indicated that for the PBS/ MWCNT nanocomposites the dimensionality of 

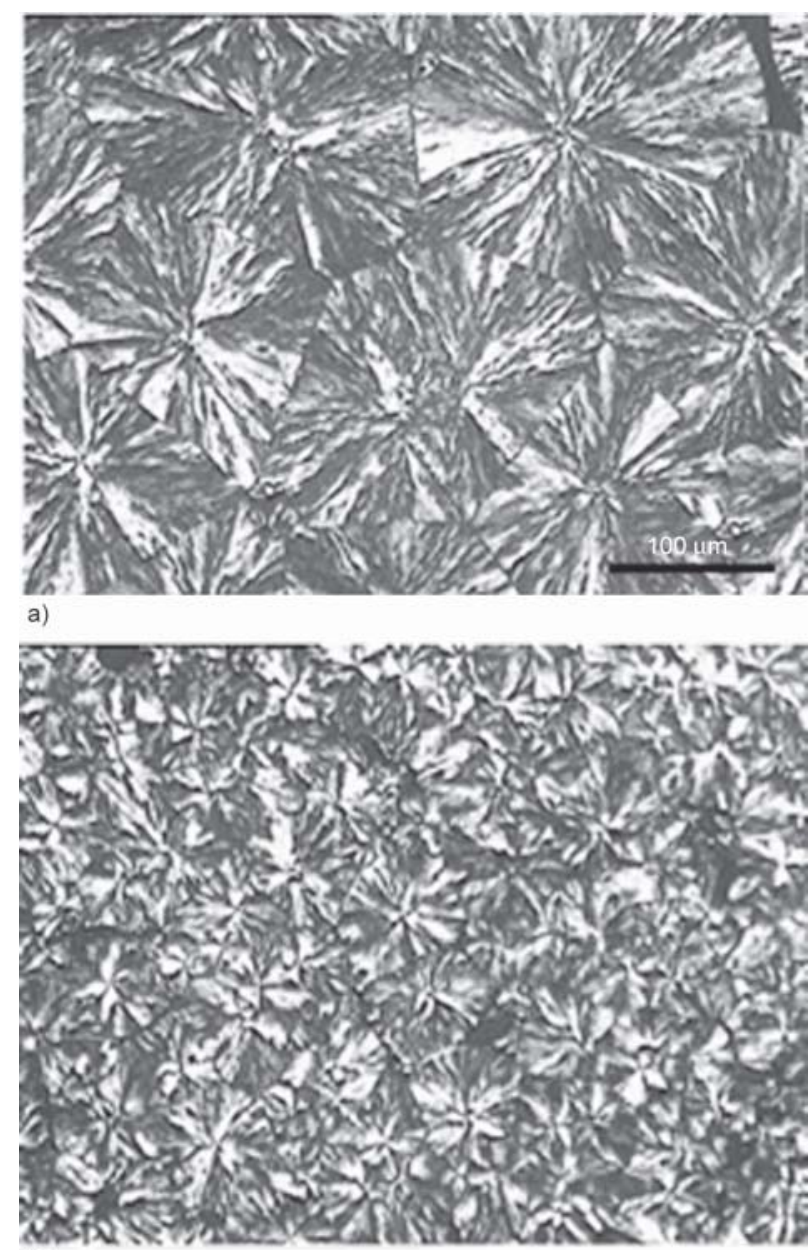

b)

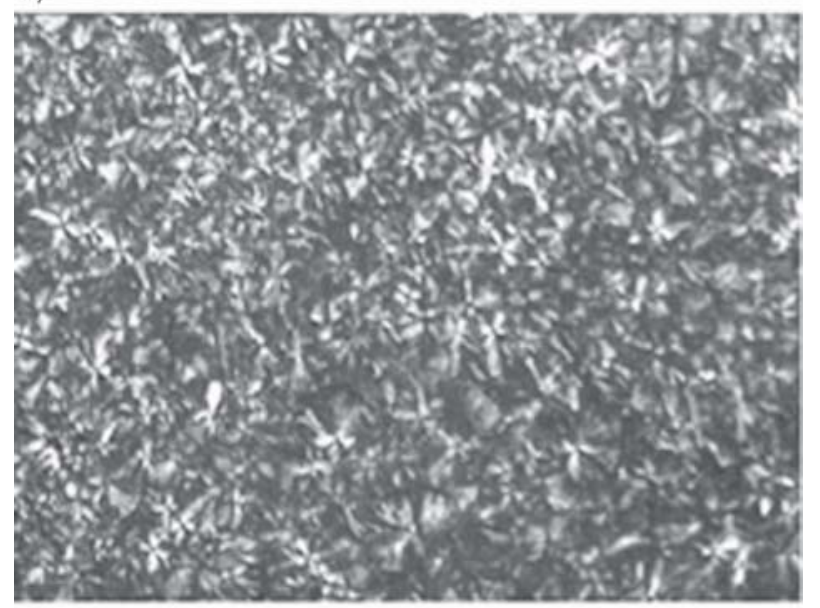

c)

Figure 4. Polarized optical micrographs for PBS/MWCNT composites with (a) $0 \%$, (b) $0.5 \%$, and (c) $1 \%$ MWCNTs. These samples were all melt crystallized at $95^{\circ} \mathrm{C}[84]$

growth switched from $3 \mathrm{D}$ to $2 \mathrm{D}$ due to the nucleation density that was greatly enhanced.

The overall isothermal crystallization rate decreased with an increase in $\mathrm{Tc}$ (in the crystallization temperature range of $82-101^{\circ} \mathrm{C}$ ) due to the low supercooling. However, the overall crystallization rate of the nanocomposites was higher than that of neat PBS in this temperature range, and increased with increasing CNTs content. This was due to the nucleation effect of the CNTs in the PBS matrix $[85,90]$.

\subsection{Conductivity}

The incorporation of electrically conductive particles into a polymer can impart electrical conductivity to the nanocomposite. The level of conductivity strongly depends on the dispersion of the filler. When the filler disperses as well separated particles in the polymer, the improvement in the electrical conductivity is limited, since a conductive path cannot be formed because of the insulating nature of the polymer matrix. The electrical conductivity can be enhanced by several orders of magnitude if a filler network is formed. In the reported literature, the MWCNTs were either used as received [89] or modified by (i) polyetheramines, (ii) $N, N^{\prime}$-dicyclohexyl carbodiimide (DCC) dehydrating agents, and (iii) nitric acid [33, 47, 83]. The effect of modified and unmodified MWCNTs on the surface resistivity of PBS/MWCNTs nanocomposites was reported [33, $47,83,89]$. The surface resistivity decreased from $>10^{16} \Omega$ (pristine PBS) to $>10^{9} \Omega$ with the addition of $3 \mathrm{wt} \%$ unmodified MWCNTs, a decrease of about $10^{7}$ fold in value of the electrical resistivity [47]. Elsewhere in the literature, the surface resistivity of the PBS/MWCNTs nanocomposites decreased from $>10^{14} \Omega$ (pristine PBS) to $>10^{3} \Omega$ (for modified MWCNTs/PBS), a decrease of about $10^{11}$ fold in the value of the electrical resistivity [33]. Ray and coworkers [83] prepared unmodified MWCNTs/PBS nanocomposites by melt blending in a batch mixer. The electrical conductivity of the nanocomposites dramatically increased compared to that of the pristine PBS sample. The in-plane conductivity increased from $5.8 \cdot 10^{-9} \mathrm{~S} \cdot \mathrm{cm}^{-1}$ for neat PBS to $4.4 \cdot 10^{-3} \mathrm{~S} \cdot \mathrm{cm}^{-1}$ for a $3 \mathrm{wt} \%$ MWCNTs-containing nanocomposite, an increase of 106 fold in the value of the electrical conductivity. The surface resistivity of the PBS/MWCNTs nanocomposites decreased from $>10^{16} \Omega$ (pristine PBS) to $>10^{6} \Omega$ for $3 \mathrm{wt} \%$ modified MWCNTs nanocomposites, a decrease of over $10^{9}$ fold. The decrease in surface resistivity of modified MWCNTs/PBS nanocomposites was larger than that of the unmodified MWCNTs/PBS, indicating the better dispersion of the modified MWCNTs in the polymer matrix compared to the unmodified MWCNTs. This implies that the percolation threshold of 
electrical conductivity was depressed. For this reason, the well dispersed MWCNTs in the PBS matrix could easily connect with each other, and subsequently form an interconnecting conductive pathway. Therefore, the amount of MWCNTs needed to construct a conductive pathway was relatively small $[33,47,89]$.

\section{PBS/PCL/CNTs nanocomposites}

\subsection{Morphology}

There is currently only one research paper available on PBS/PCL/CNTs nanocomposites [92]. The authors introduced MWCNTs into double-crystalline multiblock PBS/PCL copolymers using solution mixing and solvent casting processes. The morphologies of the resulting PBS/PCL/MWCNTs nanocomposites of different compositions are shown in a series of TEM images (Figure 5). The MWCNTs exhibited a much finer dispersion morphology in the PBS/ MWCNT nanocomposite (Figure 5b) than in the PCL/ MWCNT nanocomposite (Figure 5a). This was attributed to the wetting coefficient data for MWCNTs introduced into the binary copolymer which was calculated as 1.74 (harmonic-mean equation) or -3.43 (geometric-mean equation). According to the authors, this meant that the MWCNTs were selectively distributed in the PBS phase. Similar results were reported by Fenni et al. [93] who added graphene oxide (GO) to a $70 / 30 \mathrm{w} / \mathrm{w}$ poly(L-lactic acid) (PLLA)/ poly(butylene succinate) (PBS) blend. Their morphology results indicated microsize droplets of PBS dispersed in the PLLA phase, with most of the GO nanoparticles located in the PBS phase, although some GO stacks were also observed in the PLLA matrix. This was probably, during the preparation of the nanocomposites, the GO nanoparticles were first added to the PBS matrix via solution dispersion, and this was followed by melt blending with PLLA. The GO nanoparticles therefore had a good interaction with each other and with the PBS, but not so much with the PLLA.

In the ternary PBS/PCL/MWCNT system, a selective dispersion morphology was formed. It was assumed that the blank area in light color is the PCLenriched domain while the MWCNT located area is the PBS-enriched domain (Figure 5c). When $1 \mathrm{wt} \%$ MWCNT was loaded, varying the PBS content resulted in different dispersion states. When the PBS content was $20 \mathrm{wt} \%$ (Figure 5d), the blank area in light color was dominant and the MWCNTs were sporadically distributed in the PBS phase. This indicated that the MWCNTs containing PBS was dispersed in the PCL continuous phase. Upon increasing the PBS content to $30 \mathrm{wt} \%$ (Figure 5e), it was found that the area occupied by the MWCNTs increased, while the PCL phase was reduced. This was attributed to a cocontinuous phase between PCL and PBS at $40 \mathrm{wt} \%$ PBS, as well as the formation of a conductive MWCNTs network at this content (Figure 5f). When the loading capacity of MWCNTs increased to $3 \mathrm{wt} \%$ (Figure $5 \mathrm{~g}-5 \mathrm{i}$ ), the advantage of the selective dispersion was weakened because part of the MWCNTs spread to the PCL-enriched domain when the PBSenriched domain was saturated, especially in the $\mathrm{PBS}_{4.2}{ }^{4} \mathrm{PCL}_{6.3}{ }^{6} / \mathrm{CNTs}_{3.0}$ sample (Figure 5i).

\subsection{Mechanical properties}

Generally, carbon nanotubes improve selective mechanical properties, depending on the system employed. It is well known that a flexible polymer has a high elongation at break, as a result of its high ductility. The addition of rigid materials such as carbon nanotubes normally improves the modulus of flexible polymers at the expense of its ductility. He et al. [92] reported on the tensile properties of multiblock PBS/PCL copolymers and their nanocomposites, and found a good compromise between strength and flexibility. The authors reported an increase in the elongation at break for the multiblock PBS/PCL copolymers with an increase in PCL content, which resulted in a high ductility. However, the addition of MWCNTs resulted in a decrease in elongation at break but an increase in stiffness (Table 3). The decrease in elongation at break is due to an increase in the amount of rigid areas in the blend caused by the increasing MWCNTs content, giving rise to a reduction in the deformable polymer portion in the nanocomposites.

\subsection{Melting and crystallization behaviour}

For a double-crystalline PBS/PCL system, all the samples exhibited two crystallization peaks and two melting peaks. The variation of the composition had no obvious effect on the melting temperature, but increasing the content of one segment increased its crystallinity (especially for the PBS segment). The addition of $1 \mathrm{wt} \%$ MWCNTs to the PBS/PCL copolymer had no obvious effect on the melting temperature of both segments, but the crystallinity significantly increased when compared to the pristine PBS/PCL copolymers. For the PBS/PCL/MWCNTs nanocomposite with the lowest PBS content, the crystallinity 


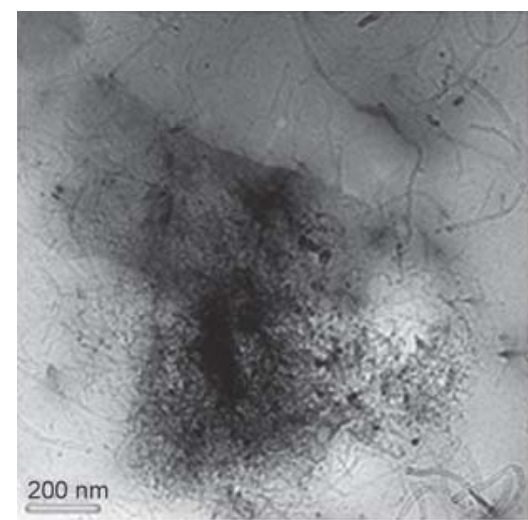

a)

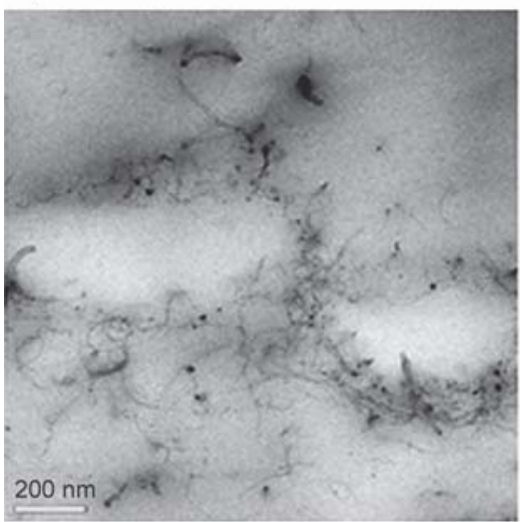

d)

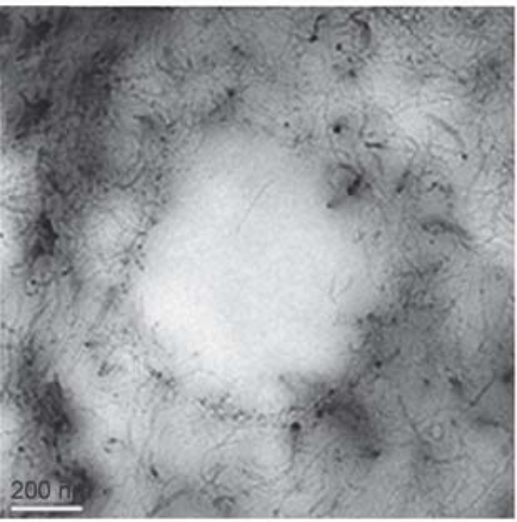

g)

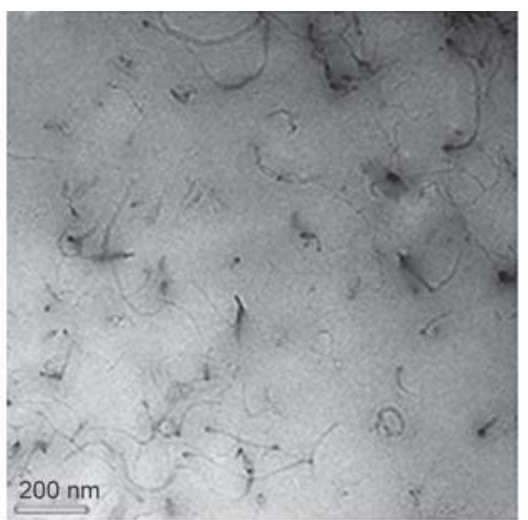

b)

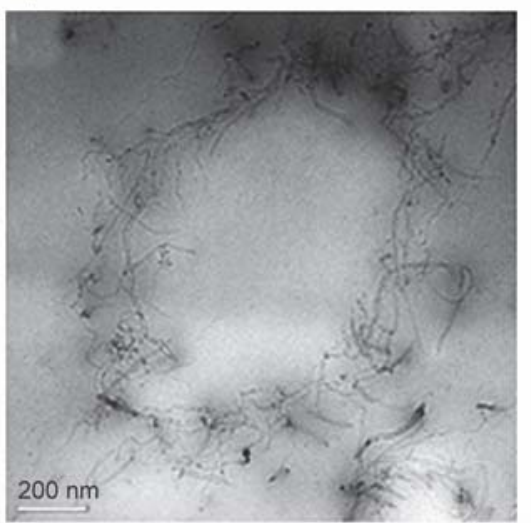

e)

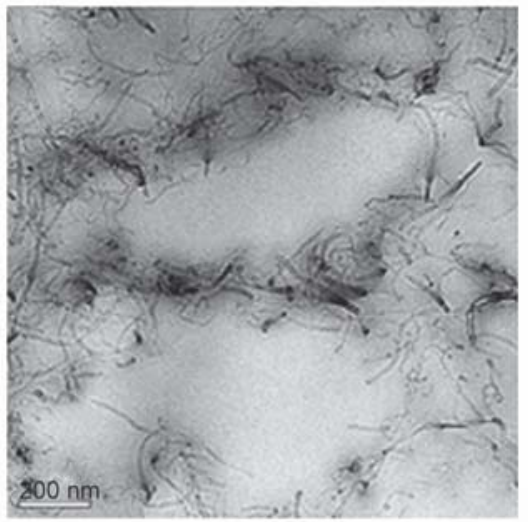

h)

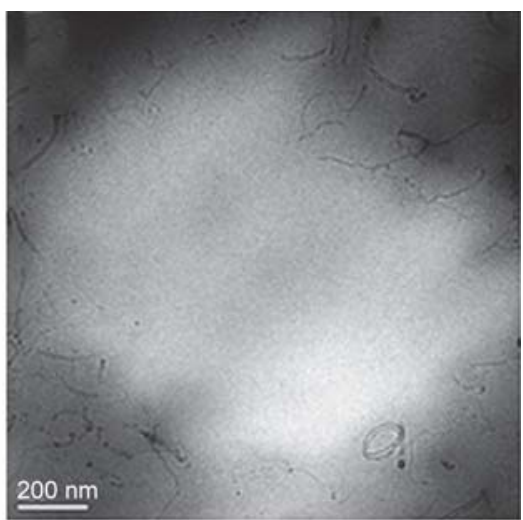

c)

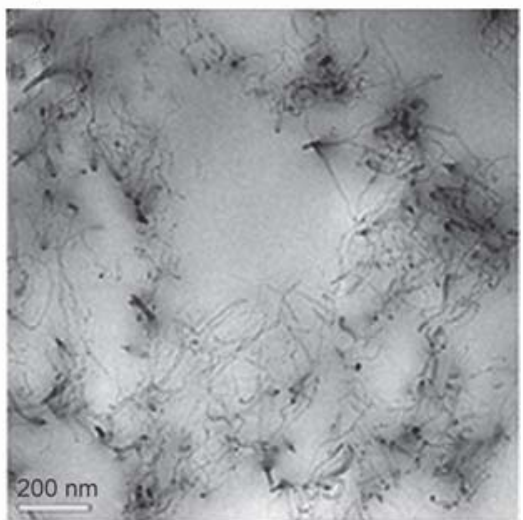

f)

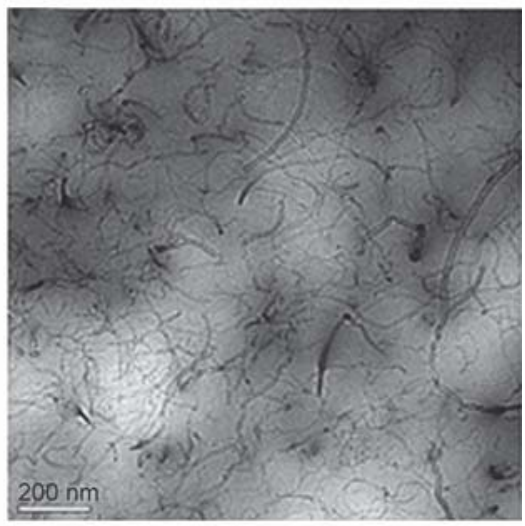

Figure 5. TEM images of (a) $\mathrm{PCL}_{6.3} / \mathrm{MWCNTs}_{1.0}$, (b) $\mathrm{PBS}_{4.2} / \mathrm{MWCNTs}_{1.0}$, (c) $\mathrm{PBS}_{4.2}{ }^{2} / \mathrm{PCL}_{6.3}{ }^{8} / \mathrm{MWCNTs}_{1.0}$, (d) $\mathrm{PBS}_{4.2}{ }^{2} \mathrm{PCL}_{6.3}{ }^{8} / \mathrm{MWCNTs}_{1 .} 0$, (e) $\mathrm{PBS}_{4.2}{ }^{3} \mathrm{PCL}_{6.3}{ }^{7} / \mathrm{MWCNTs}_{1.0}$, (f) $\mathrm{PBS}_{4.2}{ }^{4} \mathrm{PCL}_{6.3}{ }^{6} / \mathrm{MWCNTs}_{1.0}$,

(g) $\mathrm{PBS}_{4.2}{ }^{2} \mathrm{PCL}_{6.3}{ }^{8} / \mathrm{MWCNTs}_{3.0}$, (h) $\mathrm{PBS}_{4.2}{ }^{3} \mathrm{PCL}_{6.3}{ }^{7} / \mathrm{MWCNTs}_{3.0}$, and (i) $\mathrm{PBS}_{4.2}{ }^{4} \mathrm{PCL}_{6.3}{ }^{6} / \mathrm{MWCNTs}_{3.0}$ [92].

of the PBS segment was enhanced, while a slight change was reported in the PCL segment. This was attributed to the nucleating effect of a large concentration of MWCNTs in the PBS domain. It is worth noting that the nucleating effect became less significant when the PBS content decreased. For the PLLA/ PBS/GO system [94], the GO nanoparticles also acted as nucleating agents for both semicrystalline polymers. A nucleating value of about $80 \%$ was reported for GO towards PBS, which is among the highest nucleation efficiencies ever reported for this polymer. The nucleating efficiency for GO towards
PLLA was, however, only $\sim 15 \%$, because a very small amount of GO nanoparticles were located in the PLLA.

\subsection{Conductivity}

The key factor determining whether the material can respond to electricity is the electrical conductivity of the nanocomposites. The pristine PBS/PCL copolymer belongs to a typical insulator due to its low electrical conductivity value of about $10^{-15} \mathrm{~S} \cdot \mathrm{cm}^{-1}$. The introduction of $1.0 \mathrm{wt} \%$ MWCNTs significantly improved the electrical conductivity of the PBS/PCL/ 
Table 3. Mechanical properties of multiblock copolymers and nanocomposites [92].

\begin{tabular}{|l|c|c|c|c|}
\hline \multicolumn{1}{|c|}{ Samples } & $\begin{array}{c}\boldsymbol{\sigma}_{\mathbf{y}} \\
{[\mathbf{M P a}]}\end{array}$ & $\begin{array}{c}\boldsymbol{\sigma}_{\mathbf{b}} \\
{[\mathbf{M P a}]}\end{array}$ & $\begin{array}{c}\boldsymbol{\varepsilon} \\
{[\mathbf{\%}]}\end{array}$ & $\begin{array}{c}\boldsymbol{E} \\
{[\mathbf{M P a}]}\end{array}$ \\
\hline $\mathrm{PBS}_{4.2}{ }^{2} \mathrm{PCL}_{6.3}{ }^{8}$ & $8.12 \pm 2.80$ & $18.57 \pm 2.12$ & $892 \pm 38$ & $221 \pm 7$ \\
\hline $\mathrm{PBS}_{4.2}{ }^{3} \mathrm{PCL}_{6.3}{ }^{7}$ & $11.52 \pm 1.96$ & $19.47 \pm 0.76$ & $1004 \pm 94$ & $234 \pm 5$ \\
\hline $\mathrm{PBS}_{4.2}{ }^{4} \mathrm{PCL}_{6.3}{ }^{6}$ & $13.58 \pm 3.87$ & $23.73 \pm 1.23$ & $892 \pm 95$ & $237 \pm 18$ \\
\hline $\mathrm{PBS}_{4.2}{ }^{5} \mathrm{PCL}_{6.3}{ }^{5}$ & $14.89 \pm 2.49$ & $27.41 \pm 3.54$ & $746 \pm 67$ & $376 \pm 15$ \\
\hline $\mathrm{PBS}_{4.2}{ }^{6} \mathrm{PCL}_{6.3}{ }^{4}$ & $16.32 \pm 2.49$ & $36.51 \pm 5.26$ & $647 \pm 56$ & $406 \pm 37$ \\
\hline $\mathrm{PBS}_{4.2}{ }^{2} \mathrm{PCL}_{6.3}{ }^{8} / \mathrm{MWCNTs}_{1.0}$ & $13.28 \pm 1.39$ & $18.90 \pm 1.08$ & $1158 \pm 22$ & $256 \pm 22$ \\
\hline $\mathrm{PBS}_{4.2}{ }^{3} \mathrm{PCL}_{6.3}{ }^{7} / \mathrm{MWCNTs}_{1.0}$ & $13.37 \pm 1.02$ & $19.54 \pm 2.64$ & $945 \pm 125$ & $285 \pm 13$ \\
\hline $\mathrm{PBS}_{4.2}{ }^{4} \mathrm{PCL}_{6.3}{ }^{6} / \mathrm{MWCNTs}_{1.0}$ & $14.70 \pm 2.93$ & $20.80 \pm 2.49$ & $733 \pm 59$ & $380 \pm 20$ \\
\hline $\mathrm{PBS}_{4.2}{ }^{5} \mathrm{PCL}_{6.3}{ }^{5} / \mathrm{MWCNTs}_{1.0}$ & $17.52 \pm 1.24$ & $24.14 \pm 1.33$ & $723 \pm 94$ & $417 \pm 11$ \\
\hline $\mathrm{PBS}_{4.2}{ }^{6} \mathrm{PCL}_{6.3}{ }^{4} / \mathrm{MWCNTs}_{1.0}$ & $20.84 \pm 1.20$ & $28.88 \pm 2.27$ & $708 \pm 39$ & $424 \pm 24$ \\
\hline
\end{tabular}

MWCNTs nanocomposites to $6.25 \cdot 10^{-4} \mathrm{~S} \cdot \mathrm{cm}^{-1}$, so that the nanocomposites with an electrical conductive network are achieved, and an insulator transforms into a conductor. For comparison, the conductivity of PBS/MWCNTs was evaluated as $9.79 \cdot 10^{-5} \mathrm{~S} \cdot \mathrm{cm}^{-1}$, which is lower than that of PBS/ PCL/MWCNTs. The authors suggested that this could be proof of the selective dispersion of MWCNTs in the PBS domain [92].

\section{Conclusions}

Carbon nanotubes have clearly demonstrated their capability as a filler in various polyester matrices such as PCL, PBS and PC. Nanocomposites prepared through solution mixing showed no apparent aggregation, giving rise to better interfacial interactions between the polymer and the carbon nanotubes. Furthermore, functionalization of MWCNTs as well as the MWCNTs masterbatch gave rise to significant improvements in the thermal, electrical, and mechanical properties of the nanocomposites as compared to pristine MWCNTs. The masterbatch technology is also a suitable way to (i) obtain well dispersed MWCNTs nanocomposites with electrical conductivity at low amounts of nanotubes, and (ii) to limit inhalation exposure to MWCNTs in occupational settings because it operates in solvent-less environments. In all the nanocomposites, addition of a small amount of carbon nanotubes, e.g., $0.5 \mathrm{wt} \%$, was sufficient to enhance the thermal and mechanical properties, and thermal and electrical conductivities, of the nanocomposites, because adding more carbon nanotubes resulted in agglomerates due to the strong van der Waals interaction between the nanotubes at higher loadings. There is currently no published information on PBS/PC blends.

\section{Acknowledgements}

The National Research Foundation and Sasol Inzalo Foundation in South Africa is acknowledged by T.P. Gumede for financial support of the project.

\section{References}

[1] Hopewell J., Dvorak R., Kosior E.: Plastics recycling: Challenges and opportunities. Philosophical Transactions of the Royal Society B, 364, 2115-2126 (2009). https://doi.org/10.1098/rstb.2008.0311

[2] Song J. H., Murphy R. J., Narayan R., Davies G. B. H.: Biodegradable and compostable alternatives to conventional plastics. Philosophical Transactions of the Royal Society B, 364, 2127-2139 (2009). https://doi.org/10.1098/rstb.2008.0289

[3] Mdletshe T. S., Mishra S. B., Mishra A. K.: Studies on the effect of silicon carbide nanoparticles on the thermal, mechanical, and biodegradation properties of poly (caprolactone). Journal of Applied Polymer Science, 132, 42145/1-42145/9 (2015). https://doi.org/10.1002/app.42145

[4] Bhatia A., Gupta R. K., Bhattacharya S. N., Choi. H. J.: Compatibility of biodegradable poly(lactic acid) (PLA) and poly(butylene succinate) (PBS) blends for packaging application. Korea-Australia Rheology Journal 19, 125-131 (2007).

[5] Gigli M., Negroni A., Zanaroli G., Lotti N., Fava F., Munari A.: Environmentally friendly PBS-based copolyesters containing PEG-like subunit: Effect of block length on solid-state properties and enzymatic degradation. Reactive and Functional Polymers, 73, 764-771 (2013).

https://doi.org/10.1016/j.reactfunctpolym.2013.03.007

[6] Vroman I., Tighzert L.: Biodegradable polymers. Materials, 2, 307-344 (2009). https://doi.org/10.3390/ma2020307

[7] Morent R., De Geyter N., Desmet T., Dubruel P., Leys C.: Plasma surface modification of biodegradable polymers: A review. Plasma Processes and Polymers, 8, 171-190 (2011). https://doi.org/10.1002/ppap.201000153 
[8] Reddy M. M., Vivekanandhan S., Misra M., Bhatia S. K., Mohanty A. K.: Biobased plastics and bionanocomposites: Current status and future opportunities. Progress in Polymer Science, 38, 1653-1689 (2013).

https://doi.org/10.1016/j.progpolymsci.2013.05.006

[9] Babu R. P., Connor K. O., Seeram R.: Current progress on bio-based polymers and their future trends. Progress in Biomaterials, 2, 8/1-8/16 (2013).

https://doi.org/10.1186/2194-0517-2-8

[10] Fortunati E., Gigli M., Luzi F., Lotti N., Munari A., Gazzano M., Armentano I., Kenny J. M.: Poly(butylene cyclohexanedicarboxylate/diglycolate) random copolymers reinforced with SWCNTs for multifunctional conductive biopolymer composites. Express Polymer Letters, 10, 111-124 (2016).

https://doi.org/10.3144/expresspolymlett.2016.12

[11] Robeson L. M.: Polymer blends. A comprehensive review. Hanser, München (2007).

[12] Fukushima K., Feijoo J. L., Yang M-C.: Comparison of abiotic and biotic degradation of PDLLA, PCL and partially miscible PDLLA/PCL blend. European Polymer Journal, 49, 706-717 (2013).

https://doi.org/10.1016/j.eurpolymj.2012.12.011

[13] Castillo R. V., Müller A. J., Raquez J-M., Dubois P.: Crystallization kinetics and morphology of biodegradable double crystalline PLLA- $b$-PCL diblock copolymers. Macromolecules, 43, 4149-4160 (2010).

https://doi.org/10.1021/ma100201g

[14] Luyt A. S., Gasmi S.: Influence of blending and blend morphology on the thermal properties and crystallization behaviour of PLA and PCL in PLA/PCL blends. Journal of Materials Science, 51, 4670-4681 (2016). https://doi.org/10.1007/s10853-016-9784-z

[15] Ravati S., Favis B. D.: Tunable morphologies for ternary blends with poly(butylene succinate): Partial and complete wetting phenomena. Polymer, 54, 3271-3281 (2013). https://doi.org/10.1016/j.polymer.2013.04.005

[16] Reddy M. M., Mohanty A. K., Misra M.: Biodegradable blends from plasticized soy meal, polycaprolactone, and poly(butylene succinate). Macromolecular Materials and Engineering, 297, 455-463 (2012).

https://doi.org/10.1002/mame.201100203

[17] Nugroho P., Mitomo H., Yoshii F., Kume T., Nishimura K.: Improvement of processability of PCL and PBS blend by irradiation and its biodegradability. Macromolecular Materials and Engineering, 286, 316-323 (2001).

https://doi.org/10.1002/1439-

2054(20010501)286:5<316::AID-MAME316>3.0.CO;2-N

[18] Ravati S., Favis B. D.: Interfacial coarsening of ternary polymer blends with partial and complete wetting structures. Polymer, 54, 6739-6751 (2013).

https://doi.org/10.1016/j.polymer.2013.10.009
[19] Qiu Z., Komura M., Ikehara T., Nishi T.: Miscibility and crystallization behavior of biodegradable blends of two aliphatic polyesters. Poly(butylene succinate) and poly( $\varepsilon$-caprolactone). Polymer, 44, 7749-7756 (2003). https://doi.org/10.1016/j.polymer.2003.10.013

[20] Can E., Bucak S., Kinaci E., Çalikoğlu A. C., Köse G. T.: Polybutylene succinate (PBS) - polycaprolactone (PCL) blends compatibilized with poly(ethylene oxide)-blockpoly(propylene oxide)-block-poly(ethylene oxide) (PEOPPO-PEO) copolymer for biomaterial applications. Polymer-Plastics Technology and Engineering, 53, 11781193 (2014).

https://doi.org/10.1080/03602559.2014.886119

[21] Liu Q., Zhou X-M.: Preparation of poly(butylene succinate)/poly( $\varepsilon$-caprolactone) blends compatibilized with poly(butylene succinate-co- $\varepsilon$-caprolactone) copolymer. Journal of Macromolecular Science Part A: Pure and Applied Chemistry, 52, 625-629 (2015).

https://doi.org/10.1080/10601325.2015.1050634

[22] Kelnar I., Kratochvíl J., Fortelnỳ I., Kapralková L., Zhigunov A., Khunová V., Nevoralová M.: Effect of halloysite on structure and properties of melt-drawn PCL/ PLA microfibrillar composites. Express Polymer Letters, 10, 381-393 (2016).

https://doi.org/10.3144/expresspolymlett.2016.36

[23] Zhao Y., Qu J., Feng Y., Wu Z., Chen F., Tang H.: Mechanical and thermal properties of epoxidized soybean oil plasticized polybutylene succinate blends. Polymers for Advanced Technologies, 23, 632-638 (2012). https://doi.org/10.1002/pat.1937

[24] Coutinho D. F., Gomes M. E., Neves N. M., Reis R. L.: Development of micropatterned surfaces of poly(butylene succinate) by micromolding for guided tissue engineering. Acta Biomaterialia, 8, 1490-1497 (2012). https://doi.org/10.1016/j.actbio.2011.12.035

[25] Brunner C. T., Baran E. T., Pinho E. D., Reis R. L., Neves N. M.: Performance of biodegradable microcapsules of poly(butylene succinate), poly(butylene succinate-co-adipate) and poly(butylene terephthalate-coadipate) as drug encapsulation systems. Colloids and Surfaces B: Biointerfaces, 84, 498-507 (2011). https://doi.org/10.1016/j.colsurfb.2011.02.005

[26] Mizuno S., Maeda T., Kanemura C., Hotta A.: Biodegradability, reprocessability, and mechanical properties of polybutylene succinate (PBS) photografted by hydrophilic or hydrophobic membranes. Polymer Degradation and Stability, 117, 58-65 (2015).

https://doi.org/10.1016/j.polymdegradstab.2015.03.015

[27] John J., Mani R., Bhattacharya M.: Evaluation of compatibility and properties of biodegradable polyester blends. Journal of Polymer Science Part A: Polymer Chemistry, 40, 2003-2014 (2002).

https://doi.org/10.1002/pola.10297 
[28] Hassan E., Wei Y., Jiao H., Muhuo Y.: Dynamic mechanical properties and thermal stability of poly(lactic acid) and poly(butylene succinate) blends composites. Journal of Fiber Bioengineering and Informatics, 6, 8594 (2013).

https://doi.org/10.3993/jfbi03201308

[29] Lee C. W., Masutani K., Kimura Y.: Ring-opening polymerization of a macrocyclic lactone monomer isolated from oligomeric byproducts of poly(butylene succinate) (PBS): An efficient route to high-molecular-weight PBS and block copolymers of PBS. Polymer, 55, 5673-5679 (2014).

https://doi.org/10.1016/j.polymer.2014.08.028

[30] Charlier Q., Girard E., Freyermouth F., Vandesteene M., Jacquel N., Ladavière C., Rousseau A., Fenouillot F.: Solution viscosity - Molar mass relationships for poly(butylene succinate) and discussion on molar mass analysis. Express Polymer Letters, 9, 424-434 (2015).

https://doi.org/10.3144/expresspolymlett.2015.41

[31] Huang X., Li C., Zhu W., Zhang D., Guan G., Xiao Y.: Ultraviolet-induced crosslinking of poly(butylene succinate) and its thermal property, dynamic mechanical property, and biodegradability. Polymers for Advanced Technologies, 22, 648-656 (2011).

https://doi.org/10.1002/pat.1560

[32] Zaverl M., Valerio O., Misra M., Mohanty A.: Study of the effect of processing conditions on the co-injection of PBS/PBAT and PTT/PBT blends for parts with increased bio-content. Journal of Applied Polymer Science, 132, 41278/1-41278/11 (2015).

https://doi.org/10.1002/app.41278

[33] Lin C-S., Shih Y-F., Jeng R-J., Dai S. A., Lin J-J., Lee C-C.: Nanocomposites with enhanced electrical properties based on biodegradable poly(butylene succinate) and polyetheramine modified carbon nanotube. Journal of the Taiwan Institute of Chemical Engineers, 43, 322328 (2012).

https://doi.org/10.1016/j.jtice.2011.10.009

[34] Ye H-M., Chen X-T., Liu P., Wu S-Y., Jiang Z., Xiong B., Xu J.: Preparation of poly(butylene succinate) crystals with exceptionally high melting point and crystallinity from its inclusion complex. Macromolecules, 50, 5425-5433 (2017).

https://doi.org/10.1021/acs.macromol.7b00656

[35] Fan R. R., Zhou L. X., Song W., Li D. X., Zhang D. M., Ye R., Zheng Y., Guo G.: Preparation and properties of $g$-TTCP/PBS nanocomposites and its in vitro biocompatibility assay. International Journal of Biological Macromolecules, 59, 227-234 (2013).

https://doi.org/10.1016/j.ijbiomac.2013.04.051

[36] Fan R. R., Zhou L. X., Li D. X., Zhang D. M., Wu M., Guo G.: Preparation and characterization of composites based on poly (butylene succinate) and poly (lactic acid) grafted tetracalcium phosphate. Journal of Macromolecular Science Part B: Physics, 53, 296-308 (2014). https://doi.org/10.1080/00222348.2013.810104
[37] Wang L., Qiu J., Sakai E., Wei X.: The relationship between microstructure and mechanical properties of carbon nanotubes/polylactic acid nanocomposites prepared by twin-screw extrusion. Composites Part A: Applied Science and Manufacturing, 89, 18-25 (2016). https://doi.org/10.1016/j.compositesa.2015.12.016

[38] George J. J., Bhadra S., Bhowmick A. K.: Influence of carbon-based nanofillers on the electrical and dielectric properties of ethylene vinyl acetate nanocomposites. Polymer Composites, 31, 218-225 (2010). https://doi.org/10.1002/pc.20788

[39] Bhattacharya M.: Polymer nanocomposites - A comparison between carbon nanotubes, graphene, and clay as nanofillers. Materials, 9, 1-35 (2016).

https://doi.org/10.3390/ma9040262

[40] Wurm A., Lellinger D., Minakov A. A., Skipa T., Pötschke P., Nicula R., Alig I., Schick C.: Crystallization of poly( $\varepsilon$-caprolactone)/MWCNT composites: A combined SAXS/WAXS, electrical and thermal conductivity study. Polymer, 55, 2220-2232 (2014). https://doi.org/10.1016/j.polymer.2014.02.069

[41] Chin S. J., Vempati S., Dawson P., Knite M., Linarts A., Ozols K., McNally T.: Electrical conduction and rheological behaviour of composites of poly( $\varepsilon$-caprolactone) and MWCNTs. Polymer, 58, 209-221 (2015).

https://doi.org/10.1016/j.polymer.2014.12.034

[42] Pötschke P., Villmow T., Krause B.: Melt mixed PCL/ MWCNT composites prepared at different rotation speeds: Characterization of rheological, thermal, and electrical properties, molecular weight, MWCNT macrodispersion, and MWCNT length distribution. Polymer, 54, 3071-3078 (2013). https://doi.org/10.1016/j.polymer.2013.04.012

[43] Ma P-C., Siddiqui N. A., Marom G., Kim J-K.: Dispersion and functionalization of carbon nanotubes for polymer-based nanocomposites: A review. Composites Part A: Applied Science and Manufacturing, 41, 1345-1367 (2010). https://doi.org/10.1016/j.compositesa.2010.07.003

[44] Prashantha K., Soulestin J., Lacrampe M. F., Krawczak P., Dupin G., Claes M.: Masterbatch-based multi-walled carbon nanotube filled polypropylene nanocomposites: Assessment of rheological and mechanical properties. Composites Science and Technology, 69, 1756-1763 (2009). https://doi.org/10.1016/j.compscitech.2008.10.005

[45] Wu T-M., Chen E-C., Lin Y-W., Chiang M-F., Chang G-Y.: Preparation and characterization of melt-processed polycarbonate/multiwalled carbon nanotube composites. Polymer Engineering and Science, 48, 1369-1375 (2008). https://doi.org/10.1002/pen.21094

[46] Pérez R. A., López J. V., Hoskins J. N., Zhang B., Grayson S. M., Casas M. T., Puiggalí J., Muiller A. J.: Nucleation and antinucleation effects of functionalized carbon nanotubes on cyclic and linear poly( $\varepsilon$-caprolactones). Macromolecules, 47, 3553-3566 (2014). https://doi.org/10.1021/ma5005869 
[47] Shih Y. F., Chen L. S., Jeng R. J.: Preparation and properties of biodegradable PBS/multi-walled carbon nanotube nanocomposites. Polymer, 49, 4602-4611 (2008). https://doi.org/10.1016/j.polymer.2008.08.015

[48] Shokoohi S., Arefazar A.: A review on ternary immiscible polymer blends: Morphology and effective parameters. Polymers for Advanced Technologies, 20, 433 447 (2009).

https://doi.org/10.1002/pat.1310

[49] Maiti S., Suin S., Shrivastava N. K., Khatua B. B.: Low percolation threshold and high electrical conductivity in melt-blended polycarbonate/multiwall carbon nanotube nanocomposites in the presence of poly( $\varepsilon$-caprolactone). Polymer Engineering and Science, 54, 646659 (2014).

https://doi.org/10.1002/pen.23600

[50] Gumede T. P., Luyt A. S., Hassan M. K., Pérez-Camargo R. A., Tercjak A., Müller A. J.: Morphology, nucleation, and isothermal crystallization kinetics of poly( $\varepsilon$ caprolactone) mixed with a polycarbonate/MWCNTs masterbatch. Polymers, 9, 709/1-709/26 (2017).

https://doi.org/10.3390/polym9120709

[51] Ketelaars A. A. J., Papantoniou Y., Nakayama K.: Analysis of the density and the enthalpy of poly( $\varepsilon$-caprolactone)-polycarbonate blends: Amorphous phase compatibility and the effect of secondary crystallization. Journal of Applied Polymer Science, 66, 921-927 (1997). https://doi.org/10.1002/(SICI)10974628(19971031)66:5<921::AID-APP12>3.0.CO;2-Q

[52] Cheung Y. W., Stein R. S., Chu B., Wu G.: Evolution of crystalline structures of poly( $\varepsilon$-caprolactone)/polycarbonate blends. 1. Isothermal crystallization kinetics as probed by synchrotron small-angle X-ray scattering. Macromolecules, 27, 3589-3595 (1994).

https://doi.org/10.1021/ma00091a021

[53] Balsamo V., Calzadilla N., Mora G., Müller A. J.: Thermal characterization of polycarbonate/polycaprolactone blends. Journal of Polymer Science Part B: Polymer Physics, 39, 771-785 (2001).

https://doi.org/10.1002/10990488(20010401)39:7<771::AID-POLB1052>3.0.CO;2-I

[54] Cruz C. A., Paul D. R., Barlow J. W.: Polyester-polycarbonate blends. IV. Poly( $\varepsilon$-caprolactone). Journal of Applied Polymer Science, 23, 589-600 (1979). https://doi.org/10.1002/app.1979.070230228

[55] Chun Y. S., Park J., Sun J. B., Kim W. N.: Blends of polycarbonate and poly( $\varepsilon$-caprolactone $)$ and the determination of the polymer-polymer interaction parameter of the two polymers. Journal of Polymer Science Part B: Polymer Physics, 38, 2072-2076 (2000).

https://doi.org/10.1002/10990488(20000801)38:15<2072::AID-POLB120>3.0.CO;2-4

[56] Jonza J. M., Porter R. S.: Bisphenol A polycarbonate/ poly(ie-caprolactone) blends: Melting point depression and reactivity. Macromolecules, 19, 1946-1951 (1986). https://doi.org/10.1021/ma00161a028
[57] Herrera D., Zamora J-C., Bello A., Grimau M., Laredo E., Müller A. J., Lodge T. P.: Miscibility and crystallization in polycarbonate/poly( $\varepsilon$-caprolactone) blends: Application of the self-concentration model. Macromolecules, 38, 5109-5117 (2005).

https://doi.org/10.1021/ma050481c

[58] Menczel J. D., Prime R. B.: Thermal analysis of polymers. Fundamentals and applications. Wiley, New Jersey (2009). https://doi.org/10.1002/9780470423837

[59] Pan L., Pei X., He R., Wan Q., Wang J.: Multiwall carbon nanotubes/polycaprolactone composites for bone tissue engineering application. Colloids and Surfaces B: Biointerfaces, 93, 226-234 (2012). https://doi.org/10.1016/j.colsurfb.2012.01.011

[60] Yeh J-T., Yang M-C., Wu C-J., Wu C-S.: Preparation and characterization of biodegradable polycaprolactone/ multiwalled carbon nanotubes nanocomposites. Journal of Applied Polymer Science, 112, 660-668 (2009). https://doi.org/10.1002/app.29485

[61] Meng Z. X., Zheng W., Li L., Zheng Y. F.: Fabrication and characterization of three-dimensional nanofiber membrance of PCL-MWCNTs by electrospinning. Materials Science and Engineering: C, 30, 1014-1021 (2010). https://doi.org/10.1016/j.msec.2010.05.003

[62] Lee H-H., Shin U-S., Jin G-Z., Kim H-W.: Highly homogeneous carbon nanotube-polycaprolactone composites with various and controllable concentrations of ionically-modified-MWCNTs. Bulletin of the Korean Chemical Society, 32, 157-161 (2011). https://doi.org/10.5012/bkcs.2011.32.1.157

[63] Mohlala M. S., Ray S. S.: Preparation and characterization of polymer/multi-walled carbon nanotube nanocomposites. Solid State Phenomena, 140, 97-102 (2008). https://doi.org/10.4028/www.scientific.net/SSP.140.97

[64] Saeed K., Park S-Y.: Preparation and properties of multiwalled carbon nanotube/polycaprolactone nanocomposites. Journal of Applied Polymer Science, 104, 19571963 (2007).

https://doi.org/10.1002/app.25902

[65] Saeed K., Park S-Y., Lee H-J., Baek J-B., Huh W-S.: Preparation of electrospun nanofibers of carbon nanotube/polycaprolactone nanocomposite. Polymer, 47, 8019-8025 (2006).

https://doi.org/10.1016/j.polymer.2006.09.012

[66] Trujillo M., Arnal M. L., Müller A. J., Mujica M. A., de Navarro C. U., Ruelle B., Dubois P.: Supernucleation and crystallization regime change provoked by MWNT addition to poly( $\varepsilon$-caprolactone). Polymer, 53, 832-841 (2012).

https://doi.org/10.1016/j.polymer.2011.12.028 
[67] Antolín-Cerón V. H., Gómez-Salazar S., Rabelero M., Soto V., Luna-Bárcenas G., Katime I., Nuño-Donlucas S. M.: Comparative study of the thermal and mechanical properties of nanocomposites prepared by in situ polymerization of $\varepsilon$-caprolactone and functionalized carbon nanotubes. Polymer Composites, 33, 562-572 (2012).

https://doi.org/10.1002/pc.22175

[68] Qiu Z., Wang H., Xu C.: Crystallization, mechanical properties, and controlled enzymatic degradation of biodegradable poly( $\varepsilon$-caprolactone)/multi-walled carbon nanotubes nanocomposites. Journal of Nanoscience and Nanotechnology, 11, 7884-7893 (2011).

https://doi.org/10.1166/jnn.2011.4714

[69] Vega J. F., Fernández-Alcázar J., López J. V., Michell R. M., Pérez-Camargo R. A., Ruelle B., Martínez-Salazar J., Arnal M. L., Dubois P., Müller A. J.: Competition between supernucleation and plasticization in the crystallization and rheological behavior of PCL/CNT-based nanocomposites and nanohybrids. Journal of Polymer Science Part B: Polymer Physics, 55, 1310-1325 (2017). https://doi.org/10.1002/polb.24385

[70] Fillon B., Wittmann J. C., Lotz B., Thierry A.: Self-nucleation and recrystallization of isotactic polypropylene ( $\alpha$ phase) investigated by differential scanning calorimetry. Journal of Polymer Science Part B: Polymer Physics, 31, 1383-1393 (1993).

https://doi.org/10.1002/polb.1993.090311013

[71] Fillon B., Lotz B., Thierry A., Wittmann J. C.: Self-nucleation and enhanced nucleation of polymers. Definition of a convenient calorimetric 'efficiency scale' and evaluation of nucleating additives in isotactic polypropylene ( $\alpha$ phase). Journal of Polymer Science Part B: Polymer Physics, 31, 1395-1405 (1993). https://doi.org/10.1002/polb.1993.090311014

[72] Müller A. J., Arnal M. L.: Thermal fractionation of polymers. Progress in Polymer Science, 30, 559-603 (2005). https://doi.org/10.1016/j.progpolymsci.2005.03.001

[73] Sanchez-García M. D., Lagaron J. M., Hoa S. V.: Effect of addition of carbon nanofibers and carbon nanotubes on properties of thermoplastic biopolymers. Composites Science and Technology, 70, 1095-1105 (2010). https://doi.org/10.1016/j.compscitech.2010.02.015

[74] Wu T-M., Chen E-C.: Crystallization behavior of poly ( $\varepsilon$-caprolactone)/multiwalled carbon nanotube composites. Journal of Polymer Science Part B: Polymer Physics, 44, 598-606 (2006).

https://doi.org/10.1002/polb.20722

[75] Mitchell C. A., Krishnamoorti R.: Non-isothermal crystallization of in situ polymerized poly( $\varepsilon$-caprolactone) functionalized-SWNT nanocomposites. Polymer, 46, 8796-8804 (2005).

https://doi.org/10.1016/j.polymer.2005.05.101

[76] Avrami M.: Granulation, phase change, and microstructure kinetics of phase change. III. Journal of Chemical Physics, 9, 177-184 (1941).

https://doi.org/10.1063/1.1750872
[77] Lorenzo A. T., Arnal M. L., Albuerne J., Müller A. J.: DSC isothermal polymer crystallization kinetics measurements and the use of the Avrami equation to fit the data: Guidelines to avoid common problems. Polymer Testing, 26, 222-231 (2007).

https://doi.org/10.1016/j.polymertesting.2006.10.005

[78] Reiter G., Strobl G. R.: Progress in understanding of polymer crystallization. Springer, Berlin (2007).

https://doi.org/10.1007/3-540-47307-6

[79] Lorenzo A. T., Müller A. J.: Estimation of the nucleation and crystal growth contributions to the overall crystallization energy. Journal of Polymer Science Part B: Polymer Physics, 46, 1478-1487 (2008).

https://doi.org/10.1002/polb.21483

[80] Lorenzo A. T., Müller A. J., Lin M-C., Chen H-L., Jeng U-S., Priftis D., Pitsikalis M., Hadjichristidis N.: Influence of macromolecular architecture on the crystallization of $\left(\mathrm{PCL}_{2}\right)$ - $b$-( $\left.\mathrm{PS}_{2}\right)$ 4-miktoarm star block copolymers in comparison to linear PCL- $b$-PS diblock copolymer analogues. Macromolecules, 42, 8353-8364 (2009). https://doi.org/10.1021/ma901289t

[81] Müller A. J., Arnal M. L., Trujillo M., Lorenzo A. T.: Super-nucleation in nanocomposites and confinement effects on the crystallizable components within block copolymers, miktoarm star copolymers and nanocomposites. European Polymer Journal, 47, 614-629 (2011). https://doi.org/10.1016/j.eurpolymj.2010.09.027

[82] Bello A., Laredo E., Marval J. R., Grimau M., Arnal M. L., Müller A. J., Ruelle B., Dubois P.: Universality and percolation in biodegradable poly( $\varepsilon$-caprolactone)/multiwalled carbon nanotube nanocomposites from broad band alternating and direct current conductivity at various temperatures. Macromolecules, 44, 2819-2828 (2011).

https://doi.org/10.1021/ma102598h

[83] Bandyopadhyay J., Al-Thabaiti S. A., Ray S. S., Bousmina M.: Viscoelastic and electrical properties of carbon nanotubes filled poly(butylene succinate). International Polymer Processing, 29, 88-94 (2014).

https://doi.org/10.3139/217.2812

[84] Wang G., Guo B., Xu J., Li R.: Rheology, crystallization behaviors, and thermal stabilities of poly(butylene succinate)/pristine multiwalled carbon nanotube composites obtained by melt compounding. Journal of Applied Polymer Science, 121, 59-67 (2011).

https://doi.org/10.1002/app.33222

[85] Yuan L., Wu D., Zhang M., Zhou W., Lin D.: Rheological percolation behavior and isothermal crystallization of poly(butyene succinte)/carbon nanotube composites. Industrial and Engineering Chemistry Research, 50, 14186-14192 (2011). https://doi.org/10.1021/ie202039v

[86] Ray S. S., Vaudreuil S., Maazouz A., Bousmina M.: Dispersion of multi-walled carbon nanotubes in biodegradable poly(butylene succinate) matrix. Journal of Nanoscience and Nanotechnology, 6, 2191-2195 (2006). https://doi.org/10.1166/jnn.2006.368 
[87] Filizgok S., Kodal M., Ozkoc G.: Non-isothermal crystallization kinetics and dynamic mechanical properties of poly(butylene succinate) nanocomposites with different type of carbonaceous nanoparticles. Polymer Composites, in press (2018).

https://doi.org/10.1002/pc.24261

[88] Zeng R-T., Hu W., Wang M., Zhang S-D., Zeng J-B.: Morphology, rheological and crystallization behavior in non-covalently functionalized carbon nanotube reinforced poly(butylene succinate) nanocomposites with low percolation threshold. Polymer Testing, 50, 182 190 (2016).

https://doi.org/10.1016/j.polymertesting.2016.01.003

[89] Ali F. B., Mohan R.: Thermal, mechanical, and rheological properties of biodegradable polybutylene succinate/carbon nanotubes nanocomposites. Polymer Composites, 31, 1309-1314 (2010). https://doi.org/10.1002/pc.20913

[90] Tan L., Chen, Y., Zhou W., Ye S., Wei J.: Novel approach toward poly(butylene succinate)/single-walled carbon nanotubes nanocomposites with interfacial-induced crystallization behaviors and mechanical strength. Polymer, 52, 3587-3596 (2011).

https://doi.org/10.1016/j.polymer.2011.06.006
[91] Pramoda K. P., Linh N. T. T., Zhang C., Liu T.: Multiwalled carbon nanotube nucleated crystallization behavior of biodegradable poly(butylene succinate) nanocomposites. Journal of Applied Polymer Science, 111, 2938-3945 (2009).

https://doi.org/10.1002/app.29349

[92] He M-J., Xiao W-X., Xie H., Fan C-J., Du L., Deng XY., Yang K-K., Wang Y-Z.: Facile fabrication of ternary nanocomposites with selective dispersion of multiwalled carbon nanotubes to access multi-stimuli-responsive shape-memory effects. Materials Chemistry Frontiers, 1, 343-353 (2017).

https://doi.org/10.1039/c6qm00047a

[93] Fenni S. E., Monticelli O., Conzatti L., Doufnoune R., Stagnaro P., Haddaoui N., Cavallo D.: Correlating the morphology of poly(L-lactide)/poly(butylene succinate)/graphene oxide blends nanocomposites with their crystallization behavior. Express Polymer Letters, 12, 58-70 (2018).

https://doi.org/10.3144/expresspolymlett.2018.5 